NBER WORKING PAPER SERIES

\title{
PRIORS RULE: WHEN DO MALFEASANCE REVELATIONS HELP OR HURT INCUMBENT PARTIES?
}

\author{
Eric Arias \\ Horacio Larreguy \\ John Marshall \\ Pablo Querubín \\ Working Paper 24888 \\ http://www.nber.org/papers/w24888 \\ NATIONAL BUREAU OF ECONOMIC RESEARCH \\ 1050 Massachusetts Avenue \\ Cambridge, MA 02138 \\ August 2018
}

We thank the steering committee and other team members of the EGAP Metaketa initiative for illuminating discussions and useful comments. We also thank Abhijit Banerjee, Loreto Cox, Esther Duflo, Georgy Egorov, Leopoldo Fergusson, Pablo Fernandez-Vazquez, Claudio Ferraz, Jeff Frieden, Nikhar Gaikwad, Reema Hanna, Torben Iversen, Ethan Kaplan, Philip Keefer, Marko Klasnja, Stuti Khemani, Julien Labonne, Marco Larizza, Chappell Lawson, Peter Lorentzen, Tommaso Nannicini, Maria Petrova, Dina Pomeranz, Vincent Pons, Laura Schechter, Ken Shepsle, Tara Slough, Johannes Urpelainen, participants at Columbia University, the First Bruneck Workshop on the Political Economy of Federalism and Local Development at the Free University of Bozen-Bolzano, LASA 2016, NEUDC 2016, Northwestern Kellogg, University of Maryland, WESSI workshop at NYU Florence, World Bank, and WPSA 2017 for their feedback and comments. We are extremely grateful to Anais Anderson, Adriana Paz, and Alejandra Rogel, and the Data OPM and Qué Funciona para el Desarrollo teams for their implementation of this project, as well as to Juan Carlos Cano Martínez, Executive Secretary of the Guanajuato Electoral Institute, for his assistance in responding to municipal governments that tried to prevent our treatment's dissemination. We are grateful to Tommaso Nannicini and Francesco Trebbi, and Frederico Finan and Laura Schechter, for sharing their survey instruments. We thank Taylor Boas and Danny Hidalgo for sharing their experimental data from Brazil. This research was financed by the EGAP Metaketa initiative, and was approved by the Harvard Committee on the Use of Human Subjects (15-1068) and the New York University Committee on Activities Involving Human Subjects (15-10587). Our pre-analysis plan was pre-registered with EGAP, and is publicly available at egap.org/registration/760. The views expressed herein are those of the authors and do not necessarily reflect the views of the National Bureau of Economic Research.

NBER working papers are circulated for discussion and comment purposes. They have not been peer-reviewed or been subject to the review by the NBER Board of Directors that accompanies official NBER publications.

(C) 2018 by Eric Arias, Horacio Larreguy, John Marshall, and Pablo Querubín. All rights reserved. Short sections of text, not to exceed two paragraphs, may be quoted without explicit permission provided that full credit, including $(\mathrm{C}$ notice, is given to the source. 
Priors rule: When do Malfeasance Revelations Help or Hurt Incumbent Parties?

Eric Arias, Horacio Larreguy, John Marshall, and Pablo Querubín

NBER Working Paper No. 24888

August 2018

JEL No. D72,D73

\begin{abstract}
Effective policy-making requires that voters avoid electing malfeasant politicians. However, as our simple learning model emphasizing voters' prior beliefs and updating highlights, informing voters of incumbent malfeasance may not entail sanctioning. Specifically, electoral punishment of incumbents revealed to be malfeasant is rare where voters already believed them to be malfeasant, while information's effect on turnout is non-linear in the magnitude of revealed malfeasance. These Bayesian predictions are supported by a field experiment informing Mexican voters about malfeasant mayoral spending before municipal elections. Given voters' low expectations and initial uncertainty, as well as politician responses, relatively severe malfeasance revelations increased incumbent vote share on average. Consistent with voter learning, rewards were lower among voters with lower malfeasance priors, among voters with more precise prior beliefs, when audits revealed greater malfeasance, and among voters updating less favorably. Furthermore, both low and high malfeasance revelations increased turnout, while less surprising information reduced turnout.

Eric Arias

Department of Government

College of William and Mary

P.O. Box 8795

Williamsburg, VA 23187

eric.arias@wm.edu

Horacio Larreguy

Harvard University

Department of Government

1737 Cambridge Street

CGIS Knafel Building 408

Cambridge, MA 02138

hlarreguy@fas.harvard.edu

John Marshall

Columbia University

Department of Political Science

420 West 118th Street

International Affairs Building, Room 705

New York, NY 10027

jm4401@ columbia.edu

Pablo Querubín

Department of Politics

New York University

19 West Fourth Street, Room 428

New York, NY 10012

and NBER

pablo.querubin@gmail.com
\end{abstract}

An online appendix is available at http://www.nber.org/data-appendix/w24888 


\section{Introduction}

Elected politicians around the world implement policies to support economic development and alleviate poverty. The median voter in developing countries is generally poor, and thus often stands to benefit substantially from anti-poverty programs. However, the implementation of these programs is often beset by political rent seeking, including bribery (e.g. Hsieh and Moretti 2006), procurement and invoicing fraud (e.g. Ferraz and Finan 2008), and misallocated spending (e.g. Larreguy, Marshall and Snyder 2018). While policy-makers and NGOs have increasingly sought to design institutions to mitigate such agency losses, effective political accountability ultimately requires citizens to elect highly-performing politicians and sanction malfeasant politicians. Given that malfeasance in office still represents a major challenge in many developing contexts (e.g. Khemani et al. 2016; Mauro 1995), a key question is thus: when will voters hold their governments to account by punishing incumbent parties for malfeasant behavior in office?

A growing political economy literature has emphasized the importance of providing voters with information about incumbent performance in office. Negative information, such as reports revealing corruption, is typically expected to cause the electorate to screen out (e.g. Fearon 1999; Rogoff 1990) or punish (e.g. Barro 1973; Fearon 1999; Ferejohn 1986) those responsible when it is believed that politicians or parties persistently vary in competence or their efforts to represent voters' interests.

However, while several prominent studies have found that incumbent performance information promotes electoral accountability, the evidence supporting the voter learning logic is mixed. On one hand, Chang, Golden and Hill (2010), Ferraz and Finan (2008), and Larreguy, Marshall and Snyder (2018) find that media revelations of mayoral malfeasance reduce incumbent suport in Italy, Brazil, and Mexico, respectively. Banerjee et al. (2011), Buntaine et al. (2018), and Humphreys and Weinstein (2012) similarly find that disseminating incumbent performance scorecards can reduce support for poorly performing elected officials in India and Uganda. ${ }^{1}$ On the other hand, other recent field experiments by Adida et al. (2017), Boas, Hidalgo and Melo (2018), Chong et al. (2015), and de Figueiredo, Hidalgo and Kasahara (2013) find that disseminating unflattering information about national and local incumbent performance in Benin, Brazil, and Mexico often does not damage, and occasionally may even improve, incumbent electoral prospects. The effects on turnout of revealing incumbent malfeasance are similarly mixed: while Chong et al. (2015) suggest that unfavorable information may induce systemic disengagement-reducing votes for both incumbents and especially challengers-in Mexico, Banerjee et al. (2011) observe increased turnout in India.

\footnotetext{
${ }^{1}$ We discuss in detail differences between media and other forms of dissemination in the conclusion.
} 
It thus remains difficult to anticipate when or how providing information about incumbent performance might affect individuals' vote choices. Moreover, even among the findings that information induces sanctions (rewards) for low (high)-performing incumbents, it is not obvious that information's effects actually reflect the learning mechanism underpinning theories of electoral accountability. Given that these studies typically involve mass dissemination through means likely to generate common knowledge, it remains possible that information provision instead generates a public signal coordinating voters in favor of better candidates and against worse candidate without significantly updating their beliefs (e.g. Morris and Shin 2002). In fact, the studies that administer post-election surveys suggest that voting behavior changed without substantially altering voter beliefs about incumbent performance (Banerjee et al. 2011; Buntaine et al. 2018).

We argue that voters' prior beliefs can play a key role in rationalizing these mixed findings, and ultimately help to explain when and how voter learning about incumbent performance impacts turnout and vote choice. We highlight the importance of the direction and magnitude of belief updating when exposed to new information using a simple two-party model in which risk-averse voters form beliefs about the malfeasance of the incumbent party, receive expressive benefits from voting for relatively less malfeasant parties, and are subject to fixed partisan attachments.

Specifically, if voters already believe that their incumbent party is malfeasant, even revelations of relatively severe malfeasance can fail to decrease incumbent support if voters favorably or neutrally update their posterior beliefs based on information that is not more serious than expected. Even neutral updating increases incumbent support among risk-averse voters, by reducing their uncertainty over future incumbent performance. This can explain why well-intentioned interventions can sometimes produce perverse consequences in terms of supporting malfeasant politicians.

Furthermore, the implications for turnout imply a testable non-linearity. Under bimodal distributions of partisan attachments, information that induces low levels of updating reduces turnout by motivating a large mass of voters located around one mode to abstain because their relative preference between the parties no longer exceeds the costs of turning out. However, sufficiently surprising revelations - whether favorable or unfavorable-increase turnout by inducing voters who previously abstained to turn out and vote for the party shown to be less malfeasant, and by also inducing supporters around one mode to switch parties. ${ }^{2}$

We test these theoretical predictions-registered in our pre-analysis plan-using a field experiment conducted in Mexico around the 2015 municipal elections. Beyond its large population and recent shift towards a more pluralistic democracy, Mexico's relatively high (but substantially

\footnotetext{
${ }^{2}$ Similar results follow under unimodal distributions that are biased towards the party that voters learn is more malfeasant than expected.
} 
varying) levels of corruption and distrust in elected politicians across municipalities make it a wellsuited location to test our argument. Although individual incumbents could not seek re-election, voters hold parties responsible for incumbent performance in office in Mexico's party-centric system. Extending two recent empirical studies that focus on electoral responses to the outcomes of municipal audits, but with markedly different findings (Chong et al. 2015; Larreguy, Marshall and Snyder 2018), we examine how voters respond to leaflets revealing the extent to which municipal governments correctly spent federal transfers earmarked for social infrastructure projects benefiting the poor.

Across 678 electoral precincts in 26 municipalities from four central Mexican states, we randomized the dissemination of leaflets reporting the results of independent municipal audit reports to up to 200 households in rural and urban precincts in the weeks just before the election. We provided voters with one of two measures of incumbent malfeasance: the share of funds earmarked for social infrastructure projects that was spent on projects that did not benefit the poor, or the share of such funds spent on unauthorized projects. These measures ranged from $0 \%$ to $58 \%$ in our sample, with substantial variation around the mean of $21 \%$. A baseline survey was not feasible, due to financial constraints. We instead use the control group's post-election beliefs to proxy for the pre-treatment prior beliefs of treated and control voters within municipalities, and proxy for municipal-level belief updating by showing control respondents the treatment leaflet at the end of our study. A variety of tests validate these proxies.

Consistent with the theory, we find that the impact of revealing municipal audit reports on voters' support for the incumbent party depends on how the information relates to their prior beliefs. On average, voters' expectations were sufficiently low that the audit report information did not affect voters' posterior beliefs regarding incumbent party malfeasance, and ultimately increased the incumbent party's vote share by almost 3 percentage points. This average increase in vote share appears to reflect our treatment reducing the uncertainty of risk-averse voters around such beliefs, and may also reflect more effective responses by the incumbent party, in comparison with challenger parties, to our intervention.

However, our key finding is that voter learning is a central force driving the voting behavior that we observe. At both the individual and precinct levels, we show that the average effects mask substantial heterogeneity in the response of a Mexican electorate skeptical that local politicians allocate funds as legally mandated. Specifically, the increase in incumbent support induced by our treatment is concentrated among voters in municipalities in which audit reports revealed low malfeasance, voters who believed that their incumbent party was highly malfeasant, voters with less precise prior beliefs, and voters who favorably updated their posterior beliefs regarding 
incumbent party malfeasance upon receiving the information.

The prediction that malfeasance revelations non-linearly affect electoral turnout is also supported. In particular, relatively unsurprising information-20-30\% of funds spent on projects that did not benefit the poor or on unauthorized projects—depresses turnout by around 1 percentage point. Conversely, extreme cases of malfeasance-both $0 \%$ and above $50 \%$ - mobilize turnout by around 1 percentage point. This non-linearity, which fits with the bimodal distribution of voters' partisan attachment that we observe in Mexican municipalities, further underscores the importance of voters' prior beliefs in explaining how information influences voting behavior. In contrast with the idea that malfeasance revelations breed disengagement, we find little evidence to suggest that revealing more severe cases of malfeasance to voters reduces confidence in the capacity of elections to select competent politicians.

Finally, we examine party responses to our intervention. We find that voting behavior may in part be mediated by parties' reactions to the information disseminated. On one hand, voters in treated precincts recalled that both incumbent and challenger local party organizations discredited or incorporated malfeasance reports into their campaigns, especially where reported malfeasance was greatest. However, contrary to the sophisticated belief updating and voting behavior that we document among Mexican voters, politicians did not seem to account for voters' prior beliefs-or the extent to which they update based on the information received-in their responses. They thus did not differentially target precincts where voters updated more unfavorably about the incumbent after receiving the information. Although incumbent responses that are more effective than challenger responses could potentially explain the average increase in support for incumbents, party reactions therefore cannot account for the voting behavior reflecting voter updating.

Our study is the first to document sophisticated learning by voters in response to receiving incumbent performance information in a developing country. This is an important finding, especially given the low levels of education and limited access to information among Mexican voters. Moreover, the Bayesian behavior that we document helps to rationalize the mixed evidence regarding the effects of revealing malfeasance information on turnout and vote choice, and illuminate the underlying mechanisms. While previous scholars have studied the effects of disseminating information on such voting behavior and politician responses, this article makes four main contributions.

First, while previous studies have highlighted the potential importance of voters' prior beliefs about incumbent performance (Banerjee et al. 2011; Ferraz and Finan 2008; Humphreys and Weinstein 2012), we provide the first direct evidence in a developing country of the critical Bayesian interaction of prior beliefs and information content. ${ }^{3}$ This, for example, provides a rationalization

\footnotetext{
${ }^{3}$ Other studies in the EGAP Metaketa initiative also examined the updating of posterior beliefs (see
} 
of the pioneering findings of Ferraz and Finan (2008), who show that voters in Brazilian municipalities with local radio stations reward incumbents revealed not to have engaged in any corruption violations, but punish incumbents for whom more than one corruption violation was revealed, as well as the similar effects of scorecards disseminated through Indian newspapers (Banerjee et al. 2011). While these authors suggest that these results can be attributed to voters' prior beliefs, they are also consistent with public signals inducing voter coordination around better-performing incumbents without changing voters' beliefs (Morris and Shin 2002). By directly measuring prior beliefs and updating, we provide clear evidence that voter learning indeed drives voting behavior. Moreover, we show that voters can use information to keep parties - and not just individual politicians - accountable. This result has important implications for the many countries across the world with party-centric political systems and term limits on executive positions.

Our empirical focus on voters' prior beliefs most closely relates to Kendall, Nannicini and Trebbi's (2015) study of persuasive campaign messages in a single mayoral election in Italy. Their novel copula-based approach to eliciting prior beliefs demonstrates that, while voters updated from both valence and ideological campaign messages, only valence-in their case, the regional ranking of the mayor's development plan-influenced vote choice. By studying a different setting and type of intervention, our study complements and extends their findings in several ways. First, we study a developing democracy where accountability pressures, baseline political engagement and knowledge, and education helping voters internalize and utilize incumbent performance revelations are notably lower. Second, while we provide publicly available information from an independent audit agency on behalf of an NGO, Kendall, Nannicini and Trebbi's (2015) intervention is openly partisan in terms of both content and delivery. Third, extending Kendall, Nannicini and Trebbi's (2015) focus on the precision of prior beliefs, we also emphasize the intensity of updating by leveraging variation in the level of prior beliefs and variation in the signal that voters receive across 26 different municipalities. Our findings ultimately suggest that relatively uneducated voters can process and learn from complex incumbent performance information in sophisticated ways.

Second, we reinterpret previous findings suggesting that negative campaigning and revelations of malfeasance motivate voters to disengage from the political system and reduce turnout (Ansolabehere and Iyengar 1995; de Figueiredo, Hidalgo and Kasahara 2013). In particular, Chong et al.'s (2015) surprising result that revealing severe malfeasance reduces challenger turnout more than incumbent turnout does not account for how the information provided relates to voters' prior beliefs, and how this may in turn influence turnout decisions. In contrast, our non-linear explaDunning et al. forthcoming) but have generally yielded relatively inconclusive evidence, possibly since they focused primarily on the direction of updating (rather than its extent), and taken a different theoretical approach to turnout. 
nation for the relationship between malfeasance and turnout incorporates the role of voters' prior beliefs and the distribution of their partisan preferences. We thus demonstrate that malfeasance revelations can lead to either an increase or decrease in turnout, which helps to rationalize the findings of Chong et al. (2015). That is, although we do not preclude disengagement in theory, our approach nevertheless substantiates the claim that the mixed extant findings with respect to turnout may to a large extent reflect Bayesian updating. The importance of belief updating in making turnout decisions accords with Leon's (2017) finding that experimentally reducing voters' perception of fines for abstention reduced turnout in Peru, especially among the voters most indifferent between parties.

Third, our findings are also related to the literature on information and politician behavior. The findings of Besley and Burgess (2002), Casey (2015), and Snyder and Strömberg (2010) illustrate how voters' access to information affects politician responsiveness and redistributive strategies in India, Sierra Leone, and the United States, respectively. More recently, Bidwell, Casey and Glennerster (2016) and Cruz, Keefer and Labonne (2017) provide evidence from Sierra Leone and the Philippines, respectively, that politicians specifically respond to informational interventions before elections. While their findings are consistent with politicians responding to the content of the information provided, these studies do not directly assess how this content compares with voters' prior beliefs. Our findings instead indicate that, while politicians do respond to informational interventions in an attempt to counteract their electoral consequences, their responses do not always account for the sophisticated way in which voters process the information provided. The effectiveness of politician responses may then in part account for the positive average effect of information provision, but cannot fully account for voters' heterogeneous responses in line with their prior beliefs.

Finally, our findings suggest that leaflet and media dissemination campaigns might induce somewhat different effects. While the negative slope that we observe with respect to the level of reported malfeasance is similar to the media-based dissemination studied by Banerjee et al. (2011), Ferraz and Finan (2008), and Larreguy, Marshall and Snyder (2018), our positive estimates of the average effect of information provision notably differ. Although our main focus is on the slope with respect to priors and updating, the difference in the average effect is particularly interesting given that Larreguy, Marshall and Snyder (2018) examine a similar, if richer and more urban, Mexican sample. One possibility is that the wide reach of media outlets prevents politicians from specifically targeting treated precincts as they they do following localized leaflet provision. Similarly, the media might provide the type of public signal required to facilitate coordinated action (Morris and Shin 2002), potentially uniting voters against incumbents believed to be 
worse than challengers. Another possibility is that media framing of malfeasance reports implies worse performance than the raw numbers that our leaflets indicate (Iyengar 1991). We conclude by discussing these mechanisms in greater detail.

The article is structured as follows. Section 2 describes the Mexican municipal context motivating our argument. Section 3 presents a simple model highlighting the conditions under which information increases or decreases a voter's propensity to turn out and cast a ballot for the incumbent party. Section 4 explains and validates our experimental design. Sections 5 and 6, respectively, present the individual- and precinct-level results. Section 7 discusses the general equilibrium implications in terms of incumbent and challenger party responses. Section 8 concludes.

\section{Malfeasance, audits, and elections in Mexican municipalities}

Mexico's federal system is divided into 31 states (and the Federal District of Mexico City), which contain around 2,500 municipalities and 67,000 electoral precincts. Following major decentralization reforms in the 1990s (see Wellenstein, Núñez and Andrés 2006), municipal governments-the focus of this article-have played an important role in delivering basic public services and managing local infrastructure. Municipalities, which account for $20 \%$ of total government spending, are governed by mayors who are typically elected to three-year non-renewable terms. ${ }^{4}$

\subsection{Independent audits of municipal spending}

A key component of a mayor's budget is the Municipal Fund for Social Infrastructure (FISM), which represents $24 \%$ of the average municipality's budget. According to the 1997 Fiscal Coordination Law, FISM funds are direct federal transfers mandated exclusively for infrastructure projects that benefit the population living in poverty, as defined by those living in localities deemed to be marginalized by the National Population Council (CONAPO). Eligible projects include investments in the water supply, drainage, electrification, health infrastructure, education infrastructure, housing, and roads. However, voters are poorly informed about both the resources available to mayors and their responsibility to provide basic public services (Chong et al. 2015).

The use of FISM transfers is subject to independent audits. Responding to high levels of perceived mismanagement of public resources, the Federal Auditor's Office (ASF) was established in 1999 to audit the use of federal funds. Although the ASF reports to Congress, its autonomy is enshrined in the constitution, and it has the power to impose fines, recommend economic sanctions,

\footnotetext{
${ }^{4}$ Re-election became possible for incumbents in most states as of July 2018.
} 
and file or recommend criminal lawsuits against public officials. The ASF selects around 150 municipalities for audit each year, based primarily on the relative contribution of FISM transfers to the municipal budget, historical performance, factors that raise the likelihood of mismanagement, and whether the municipality has recently been audited (including concurrent federal audits of other programs) (see Auditoría Superior de la Federación 2014). Around a quarter of municipalities have been audited at least once over the past decade. The municipalities to be audited in a given year are announced after the funds disbursed for a given fiscal year have been spent.

Audits address the spending, accounting, and management of FISM funds from the previous fiscal year. Although the ASF's reports categorize the use of FISM funds in various ways, we focus on two key dimensions of mayoral malfeasance documented in the audit reports (that are not necessarily mutually exclusive): (1) the share of funds spent on social infrastructure projects that do not directly benefit the poor and (2) the share of funds spent on unauthorized projects, which includes the diversion of resources to non-social infrastructure projects (e.g. personal expenses and election campaigns ${ }^{5}$ ) and funds that are not accounted for. The results for each audited municipality are reported to Congress in February the year after the audit was conducted, and are made publicly available on the ASF's website, asf.gob.mx. Despite their public release, voters are generally poorly informed about the ASF and media coverage of individual municipalities is mixed.

According to the ASF's audit reports released between 2007 and 2015, 8\% of audited funds were spent on projects that did not benefit the poor, while $6 \%$ were spent on unauthorized projects. In one case, the mayor of Oaxaca de Juárez created a fake union to collect payments, presided over public works contracts without offering a public tender, diverted advertising and consulting fee payments, and failed to document spending amounts. ${ }^{6}$ In another instance, nine municipal governments in the state of Tabasco-Centro, Balancán, Cárdenas, Centla, Jalapa, Jonuta, Macuspana, Tacotalpa and Tenosique - diverted resources to fund the 2012 electoral campaigns of their parties' candidates. ${ }^{7}$ Given that the ASF's reports capture only one dimension of malfeasance, it is thus unsurprising that $42 \%$ of voters do not believe that municipal governments use public resources honestly (Chong et al. 2015).

\footnotetext{
${ }^{5}$ Such spending is similar to the corruption identified by similar audits in Brazil (Ferraz and Finan 2008). ${ }^{6}$ BBM Noticias, “ASF: desvió Ugartchechea 370.9 mdp,” October 21, 2013, here.

${ }^{7}$ Tabasco Hoy, "Pagaron pobres campañas 2012," March 6, 2014, here.
} 


\subsection{Municipal elections}

Traditionally, local political competition has been between either the populist Institutional Revolutionary Party (PRI) and the right-wing National Action Party (PAN), or between the PRI and its left-wing offshoot, the Party of the Democratic Revolution (PRD). Due to regional bases of political support and highly localized influence within municipalities, local politics is typically dominated by one or two main parties. In order to get elected, the three large parties often subsume smaller parties into municipal-level coalitions. ${ }^{8}$ Moreover, as Appendix Figure A1 shows, two-party dominance is reflected in the generally bimodal distribution of voter partisanship within municipalities, once differences in the average ideological positions are accounted for. In the municipal elections that we study, the average effective number of political parties by vote share at the precinct and municipal levels remains consistently around 2.5. ${ }^{9}$ By means of comparison, the US presidential elections between 1992 and 2016 had an average of 2.2 effective parties, while Mexican presidential elections between 1994 and 2012 had an average of 3.1 effective parties.

Although economic and criminal punishments for misallocating funds are relatively rare, there are good reasons to believe that voters will hold the incumbent party responsible, even when individual mayors cannot be re-elected. First, voters are considerably better informed about political parties than about individual politicians (e.g. Chong et al. 2015; Larreguy, Marshall and Snyder forthcoming). Crucially for political accountability, $80 \%$ of voters in our survey can correctly identify the party of their municipal incumbent. Second, Mexico's main parties have differentiated candidate selection mechanisms that deliver candidates with similar attributes (Langston 2003). For example, $74 \%$ of voters in our survey believe that if the current mayor is malfeasant, then another candidate from the same party is at least somewhat likely to also be malfeasant. Third, Larreguy, Marshall and Snyder (2018) and Marshall (2018), respectively, find that when Mexican voters have access to local media, they punish municipal incumbent parties for malfeasance and elevated homicide rates before elections. Moreover, the surveys we conducted for this study show that $74 \%$ and $72 \%$ of respondents in control precincts, respectively, regard fighting poverty and honesty as important or very important when deciding which candidate to vote for.

However, the evidence regarding electoral sanctioning of Mexico's incumbent parties in response to revelations of malfeasant behavior is mixed. Larreguy, Marshall and Snyder (2018)

${ }^{8}$ These smaller parties typically benefit by receiving sufficient votes to maintain their registration. However, the National Regeneration Movement (MORENA) stood for the first time in 2015, and made headway against this hegemony at the national level, obtaining $9 \%$ of the federal legislative vote.

${ }^{9}$ The effective number of parties is given by $\frac{1}{\sum_{p \in \mathbb{P}} V_{p}^{2}}$, where $V_{p}$ is the vote share of party $p$ (Laakso and Taagepera 1979). 
observe large electoral penalties among voters with access to broadcast media outlets incentivized to report local news. Exploiting plausibly exogenous variation in the release of audit reports prior to elections and access to radio and television stations across the country, they find that an additional local media station decreases the vote share of an incumbent party revealed just before the election to have spent significant quantities of FISM funds inappropriately by around one percentage point. This evidence supports the standard electoral accountability model (e.g. Barro 1973; Fearon 1999; Ferejohn 1986; Rogoff 1990).

Conversely, in a field experiment conducted in 12 municipalities across three states, Chong et al. (2015) find evidence that information about severe incumbent malfeasance breeds disengagement. Disseminating leaflets to voters on audit report outcomes, they instead find that, while incumbent support declines when the incumbent is revealed to be highly malfeasant, challenger support also declines at least as much. They speculate that such broad-based disengagement, which is also observed through reduced partisan attachment to the incumbent, reflects an equilibrium in which voters disengage because they believe that all politicians are malfeasant. ${ }^{10}$ The disjuncture between these accountability and disengagement findings, which cover the same information over the same period, exemplifies the more general need for a more refined theory capable of explaining when and why different types of information impact voters differently.

\section{Information, prior beliefs, and voting behavior}

We now explore potential empirical implications of providing information about incumbent malfeasance for electoral accountability. The first insight of our simple learning model is that the impact of information on voters' posterior beliefs_-and ultimately their vote choice_-depends on how the information revealed relates to voters' prior beliefs. While high levels of malfeasance are clearly bad news, it is not obvious whether voters will reward or punish incumbent parties for low (but non-zero) levels of malfeasance (e.g. Banerjee et al. 2011; Ferraz and Finan 2008). Our second insight concerns turnout: with a positive cost of voting and a bimodal distribution of voters' partisan attachment, information relatively close to voters' prior beliefs may reduce turnout, while major departures can cause wholesale shifts in support from the incumbent to a challenger (or vice versa).

\footnotetext{
${ }^{10}$ In the context of our model below, this could be the result of reducing the expressive benefits of voting relative to the cost of turning out.
} 


\subsection{Theoretical model}

We consider a simple decision-theoretic model in which a unit mass of risk-averse voters update their posterior beliefs about a party's malfeasance based on informative signals, and choose between voting for incumbent party $I$, voting for challenger party $C$, and abstaining. ${ }^{11}$ Since twoparty competition is found in most parts of Mexico, this assumption provides a good approximation of political competition in most Mexican municipalities.

Voters receive expressive utility from voting for the relatively better party, and only turn out if parties are sufficiently different in terms of the utility that voters expect to obtain from either of them (see Larreguy, Marshall and Querubín 2016). ${ }^{12}$ We therefore do not assume that voters believe their vote is pivotal (see e.g. Brennan and Hamlin 1998). For analytical simplicity, we model the expected utility that voter $i$ associates with electing party $p \in\{I, C\}$ as the sum of fixed partisanship and an exponential function of expected malfeasance: ${ }^{13}$

$$
U_{i}^{p}= \begin{cases}\delta_{i}+\mathbb{E}\left[-\exp \left(\theta_{I}\right)\right] & \text { if } p=I \\ \mathbb{E}\left[-\exp \left(\theta_{C}\right)\right] & \text { if } p=C\end{cases}
$$

where $\theta_{p} \in \mathbb{R}$ is the underlying level of malfeasance of party $p,{ }^{14}$ and $\delta_{i} \in \Gamma \subseteq \mathbb{R}$ is a positive or negative partisan bias towards the incumbent. The partisan bias $\delta_{i}$ is independently and identically distributed across voters according to cumulative distribution function $F$, and could reflect durable partisan attachments or shocks occurring before the election that are uncorrelated with prior beliefs and signals of malfeasance. In this model, voters therefore receive greater expressive utility from voting for less malfeasant parties, especially when they are relatively certain that the party is relatively clean, while malfeasance and partisanship are substitutes. The exponential functional form was chosen to incorporate (constant absolute) risk aversion - an influential determinant of voting behavior in Mexico (e.g. Cinta 1999; Magaloni 2006; Morgenstern and Zechmeister 2001)—in a tractable manner. Finally, let $c>0$ be the cost of turning out to vote.

A voter only turns out to vote if the difference in expected utility between the two parties is

\footnotetext{
${ }^{11}$ In the model, we abstract from party attempts to counteract the effect of scandal exposure. Empirically, we find some evidence of such responses. However, as explained below, this operates alongside, rather than in place of, voter updating of posterior beliefs.

${ }^{12}$ In the relatively large municipalities of our sample, voters are unlikely to perceive themselves as pivotal.

${ }^{13}$ The theory can be easily extended to incorporate the ban on re-election by allowing for imperfect within-party candidate correlations. Provided that candidates within parties are sufficiently similar, the forces underpinning our results remain.

${ }^{14}$ The latent malfeasance dimension, and the signal described below, are modeled with unbounded support to simplify the analysis using a normal learning framework.
} 
large enough. Conditioning on voting, individuals cast their vote for their most preferred party. Consequently, $i$ votes for the incumbent party $I$ if $\Delta_{U_{i}}:=U_{i}^{I}-U_{i}^{C} \geq c$, votes for the challenger party $C$ if $-\Delta_{U_{i}} \geq c$, and abstains if $\left|\Delta_{U_{i}}\right|<c{ }^{15}$

Voters are uncertain about the underlying malfeasance $\theta_{p}$ of both the incumbent and challenger parties, and learn from a signal about party malfeasance in a Bayesian fashion. In particular, we assume that all voters share the same normally distributed prior beliefs about the malfeasance of each party $p$, distributed according to $N\left(\mu_{p}, \sigma_{p}^{2}\right)$, where $\lambda_{p}:=1 / \sigma_{p}^{2}$ denotes the precision of the prior beliefs. Focusing on the case where voters only receive an audit report documenting malfeasance that pertains to the incumbent, voters observe a signal $s_{I}$ drawn from a normal distribution of signals $N\left(\theta_{I}, \tau_{I}^{2}\right)$ centered on the incumbent's true (but unknown) malfeasance level $\theta_{I}$. The known precision of this signal, $\rho_{I}:=1 / \tau_{I}^{2}$, could reflect the fact that the audit report may only capture one dimension of an incumbent's malfeasance. For simplicity, we consider the case where the malfeasance of each party $p$ is known to be independently distributed. ${ }^{16}$ As we show empirically below, signals of incumbent performance do not cause voters to systematically change their posterior beliefs about the challenger.

After receiving a signal of incumbent malfeasance $s_{I}$, voters update their posterior beliefs about the incumbent's malfeasance using Bayes' rule:

$$
N\left(\mu_{I}+\kappa_{I} \Delta_{I}, \frac{1}{\lambda_{I}+\rho_{I}}\right)
$$

where $\kappa_{I}:=\frac{\rho_{I}}{\lambda_{I}+\rho_{I}}$ captures the relative precision of the signal, and $\Delta_{I}:=s_{I}-\mu_{I}$ is the difference between the signal and voters' mean prior belief about $I$. Higher values of $\kappa_{I}$ indicate that the signal is relatively more precise than voters' prior beliefs, while positive values of $\Delta_{I}$ denote signals that the incumbent is more malfeasant than voters previously had believed. Henceforth, we refer to $\Delta_{I}$ as the extent of the unfavorable updating by voters. Moreover, the extent of such updating is greater when the signal is relatively precise in comparison with voters' prior beliefs. Because the malfeasance of parties is assumed to be independent, voters do not update about $\theta_{C}$. New information also increases the precision of voters' posterior beliefs, since $\frac{1}{2\left(\lambda_{I}+\rho_{I}\right)}<\frac{1}{\lambda_{I}}$.

${ }^{15}$ An alternative specification of expressive utility, in which voters vote for $p$ if $U_{i}^{p}>\max \left\{U_{i}^{-p}, c\right\}$, would complicate our analysis but yield qualitatively similar comparative statics for the incumbent party's vote share. However, because $U_{i}^{C}$ is not affected by a signal that is uninformative about $C$, the total number of votes for $C$ would not be affected; thus, turnout would be monotonic in $s_{I}$. Our empirical analysis suggests that neither implication holds.

${ }^{16}$ At the cost of mathematical complexity this could be relaxed, and would yield similar results for a sufficiently small correlation between $s_{I}$ and $\theta_{C}$. Intuitively, this is because an imperfect correlation between types means that the signal is more informative about $I$ than $C$. 


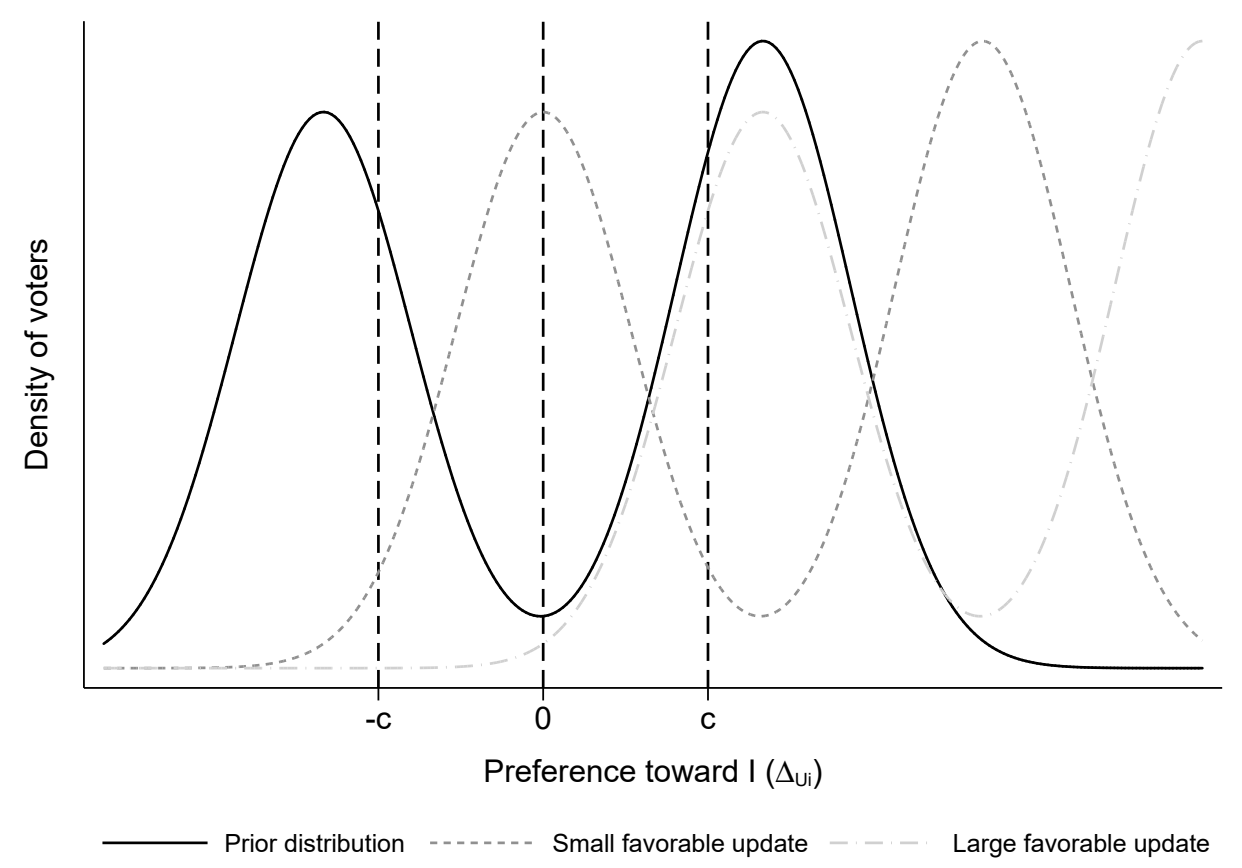

Figure 1: Vote choice and distributions of voters

A signal of low incumbent malfeasance (i.e. $s_{I}<\mu_{I}$ ) increases the relative utility of voting for $I$ by reducing both the incumbent's expected malfeasance and $i$ 's uncertainty about the incumbent's malfeasance. This is reflected in the difference in the utility of voting for each party, as perceived by voter $i$ :

$$
\Delta_{U_{i}}=\delta_{i}-\exp \left[\mu_{I}+\kappa_{I} \Delta_{I}+\frac{1}{2\left(\lambda_{I}+\rho_{I}\right)}\right]+\exp \left[\mu_{C}+\frac{1}{2 \lambda_{C}}\right]
$$

where the $\frac{1}{2\left(\lambda_{I}+\rho_{I}\right)}$ and $\frac{1}{2 \lambda_{C}}$ terms reflect voters' risk aversion. Integrating over the distribution of voter partisan biases, we obtain the following results pertaining to the share of voters $V_{I}$ turning out for the incumbent party:

Proposition 1 (Incumbent vote share). Receiving a signal $s_{I}$ of incumbent malfeasance increases incumbent vote share $V_{I}$, relative to receiving no signal, if and only if $\Delta_{I}<\frac{1}{2 \lambda_{I}}$. This difference in $V_{I}$ is decreasing in $s_{I}$ and $\Delta_{I}$ and increasing in $\mu_{I}$ (provided that $\kappa_{I}$ is sufficiently large), and the magnitude of the difference is generally decreasing in $\lambda_{I}$.

Proof. All proofs are in the Appendix.

The effect of information thus crucially depends on how the signal relates to voters' prior 
beliefs. The effect on the incumbent party's vote share is intuitively illustrated in Figure 1, which plots the distribution of voters by their relative preference $\Delta_{U_{i}}$ for the incumbent. Voters to the right, with higher values of $\Delta_{U_{i}}$, are more likely to turn out for $I$. We can thus analyze how the key parameters in our model affect voting behavior by shifting the distribution of voters along the $\Delta_{U_{i}}$ axis. As illustrated by the dotted distribution, a weak signal that the incumbent is less malfeasant than voters initially believed results in a small decrease in $\Delta_{I}$ as well as a reduction in the risk of voting for $I$. This produces a commensurate shift in the distribution of relative voter preferences to the right. This unequivocally increases the number of voters who support $I$ and decreases the number of voters supporting $C$. A signal revealing greater malfeasance than initially believed will reduce the incumbent party's vote share, provided that the signal is strong enough to overcome the reduction in risk aversion (hence the condition $\Delta_{I}<\frac{1}{2 \lambda_{I}}$ ). Similarly, a decrease in voters' prior beliefs about incumbent malfeasance (i.e. lower $\mu_{I}$ ) also shifts the distribution to the right and increases the incumbent's vote share when the signal is relatively precise (i.e. $\rho_{I}$ is high). Finally, an increase in the precision of a voter's prior belief (i.e. higher $\lambda_{I}$ ) generally diminishes the magnitude of these effects (see Appendix for more details); this intuitively reflects the lower weight attached to signals received by voters already possessing precise beliefs.

While the incumbent vote share results hold for any distribution $F$ of partisan attachments, the effect of providing information about the incumbent on overall turnout $T$ depends on the shape and position of $F$ and the extent to which information induces updating:

Proposition 2 (Turnout). Receiving a signal $s_{I}$ of incumbent malfeasance ambiguously affects turnout T: T increases (decreases) when $F\left(\bar{\delta}_{C}\right)-F\left(\hat{\delta}_{C}\right)-\left[F\left(\bar{\delta}_{I}\right)-F\left(\hat{\delta}_{I}\right)\right]>(<) 0$, where $\bar{\delta}_{p}$ and $\hat{\delta}_{p}$ denote the points of indifference between voting for party $p$ and not voting, respectively, with and without the signal. This effect is increasing (decreasing) in $s_{I}$ when $F^{\prime}\left(\bar{\delta}_{C}\right)-F^{\prime}\left(\bar{\delta}_{I}\right)>(<) 0$.

To illustrate the intuition, consider the case of receiving $s_{I}<\mu_{I}$. This signal of lower-than-expected incumbent malfeasance has two effects, again by shifting voter expectations and reducing uncertainty. First, it induces some voters who would not otherwise have voted to turn out for $I$. Second, the signal induces some voters who would otherwise have voted for $C$ not to turn out. The relative masses of these conflicting effects on turnout determine whether turnout increases or decreases.

To produce sharper empirical predictions, we focus on the empirically prevalent case in which voter partisan attachments are bimodally distributed and voters at each mode turn out for different parties. Formally, this entails $m_{C} \leq \hat{\delta}_{C}<\hat{\delta}_{I} \leq m_{I}$, where $m_{p}$ is the mode for each party and $\hat{\delta}_{p}$ is the cut point where voters are indifferent between abstaining and voting for party $p$. In many electoral contexts, including Mexico, such a distribution is a reasonable approximation. As noted above, the geographic dispersion of party strength ensures that most races are effectively two-party races. 
Furthermore, Appendix Figure A1 shows that voter partisanship is generally bimodally distributed within municipalities.

Under such a distribution, the effect of information provision is non-linear in the severity of the malfeasance revealed. This is most intuitively illustrated graphically using the example in Figure 1. The dark gray dotted distribution shifted slightly to the right shows that a small update in favor of the incumbent can cause more initial $C$ voters to abstain than initial abstainers to turn out and vote for $I$. This is easy to see by comparing the mass under each distribution over the interval $[-c, c]$. However, a sufficiently large favorable update about the incumbent — which leads the light gray dashed distribution to shift further to the right-induces initial $C$ supporters to vote for $I$ rather than abstain. It is easy to see that, conditional on receiving a sufficiently surprising signal, the provision of information will eventually increase turnout for any bimodal distribution in which the voters at each mode initially turn out for different parties. The following corollary of Proposition 2 proves this non-linear relationship:

Corollary 1 (Non-linear effects on turnout under bimodal partisanship distributions). Assume that $F$ is bimodal with modes $m_{C}$ and $m_{I}$, where $m_{C} \leq \hat{\delta}_{C}<\hat{\delta}_{I} \leq m_{I}$ and $F^{\prime}\left(\hat{\delta}_{C}\right) \neq F^{\prime}\left(\hat{\delta}_{I}\right)$. The effect of receiving a signal $s_{I}$ of incumbent malfeasance on turnout is positive for $s_{I} \leq s^{*}$ and $s_{I} \geq s^{* *}>s^{*}$, and is negative for some $s \in\left(s^{*}, s^{* *}\right)$.

Similar results hold for unimodal distributions when the modal voter initially turns out. ${ }^{17}$

\subsection{Empirical implications}

The model generates various comparative static predictions. We focus on the impact of providing voters with a signal of incumbent malfeasance, $s_{I}$, via a treatment containing information pertaining to mayoral malfeasance. We now enumerate the key hypotheses that our experiment is designed to test empirically; all hypotheses were registered in our pre-analysis plan.

We first consider how revelations of incumbent malfeasance affect voters' posterior beliefs regarding the incumbent party's malfeasance (i.e. $\theta_{I}$ ), as well as their vote choice. As equation (2) shows, the direction of updating from signal $s_{I}$ depends on voters' prior expectations, denoted $\mu_{I}$. The effect is thus context dependent, reflecting both the nature of the information provided and voters' prior beliefs regarding the incumbent party's malfeasance.

First, if voters already believe that the incumbent party is malfeasant (i.e. high $\mu_{I}$ ), a signal that indicates high malfeasance has a smaller impact on posterior beliefs and the incumbent party's vote

\footnotetext{
${ }^{17}$ Assuming the modal voters initially support $C$, then moderately good news about $I$ induces the modal voters to abstain, while very good news causes the modal voter to support $I$. Note that this result depends on the weight in the tails of the distribution.
} 
share. Second, voters who already have precise prior beliefs about the incumbent's malfeasance (i.e. low $\kappa_{I}$ or high $\lambda_{I}$ ) are less responsive to new information in either direction. Third, voters update their posterior beliefs more favorably (unfavorably) about the incumbent party's malfeasance upon learning that the incumbent is relatively clean (malfeasant). Finally, the extent of voter belief updating reflects the difference between the signal and voters' prior beliefs (i.e. $\Delta_{I}$ ). These implications are summarized in the following hypothesis:

H1 (Posterior beliefs). The effect of providing information about an incumbent's malfeasance on voters' posterior beliefs about whether the incumbent party is malfeasant is:

(a) Decreasing in voters' prior beliefs that the incumbent party is malfeasant.

(b) Decreasing in magnitude among voters with more precise prior beliefs.

(c) Increasing in the severity of the reported malfeasance.

(d) Increasing in the extent to which the information is worse than voters' prior beliefs (unfavorable updating).

These empirical predictions regarding voter posterior beliefs analogously imply the following effects on the incumbent party's vote share:

H2 (Incumbent party vote share). The effect of providing information about an incumbent's malfeasance on the incumbent party's vote share is:

(a) Increasing in voters' prior beliefs that the incumbent party is malfeasant.

(b) Decreasing in magnitude among voters with more precise prior beliefs.

(c) Decreasing in the severity of the reported malfeasance.

(d) Decreasing in the extent to which the information is worse than voters' prior beliefs (unfavorable updating).

As shown above, new information is predicted to have a non-linear effect on turnout when voters are bimodally distributed and voters at each mode initially turn out for different parties, as is generally the case in Mexico. In particular, shockingly favorable or unfavorable revelations motivate voters who previously abstained to turn out to vote, and induces voters to switch parties, while relatively unsurprising-but nevertheless informative-favorable (unfavorable) information induces challenger (incumbent) partisans to become relatively indifferent between the parties and abstain from voting. While this logic does not yield clear predictions for the average effect of new information or its linear interaction with the level of malfeasance reported, it clearly predicts that: 


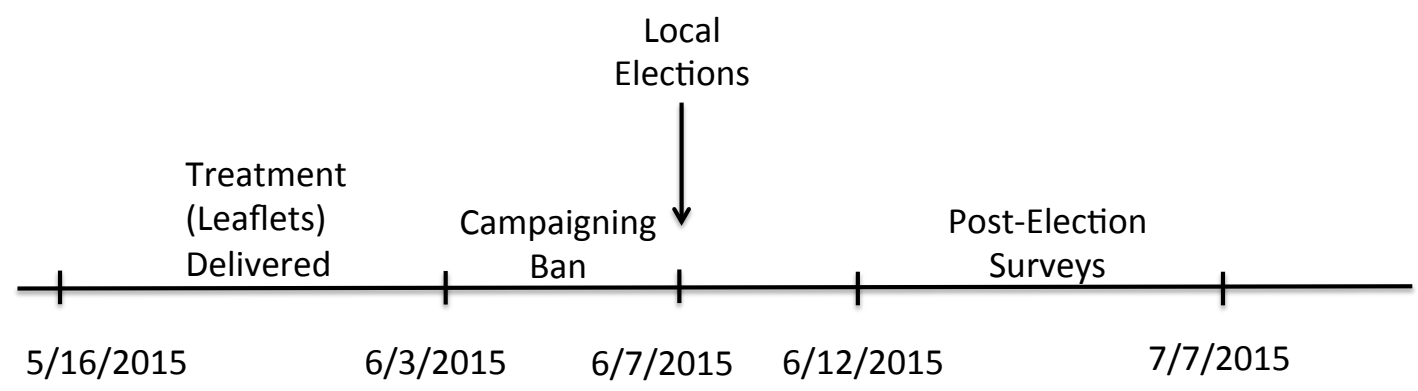

Figure 2: Timeline of the experiment's implementation

H3 (Turnout). Providing information reporting sufficiently high and low levels of incumbent malfeasance increases electoral turnout, while intermediate levels of reported malfeasance decrease turnout.

\section{Experimental design}

We designed a field experiment to test this theory. We focus on Mexico's June 7, 2015 municipal elections, which were held concurrently with state and federal legislative elections. We examine the effect of providing voters in 678 electoral precincts with the results of audit reports documenting the municipal use of federal transfers designated for infrastructure projects that benefit the poor. We first explain our sample selection, and then outline our information interventions, randomization, and estimation strategy. Figure 2 illustrates the experiment's timeline.

\subsection{Sample selection}

Our study focuses on 26 municipalities in the central states of Guanajuato (seven municipalities), México (14 municipalities), San Luis Potosí (four municipalities), and Querétaro (one municipality). These municipalities are shown in Figure 3; the average municipality contains 259,000 registered voters. In addition to the fact that they held elections in $2015,{ }^{18}$ these four states were

\footnotetext{
${ }^{18}$ Municipal elections reflect state electoral cycles, which are staggered across years. On June 7, 2015, 15 states and the federal district held simultaneous local elections.
} 


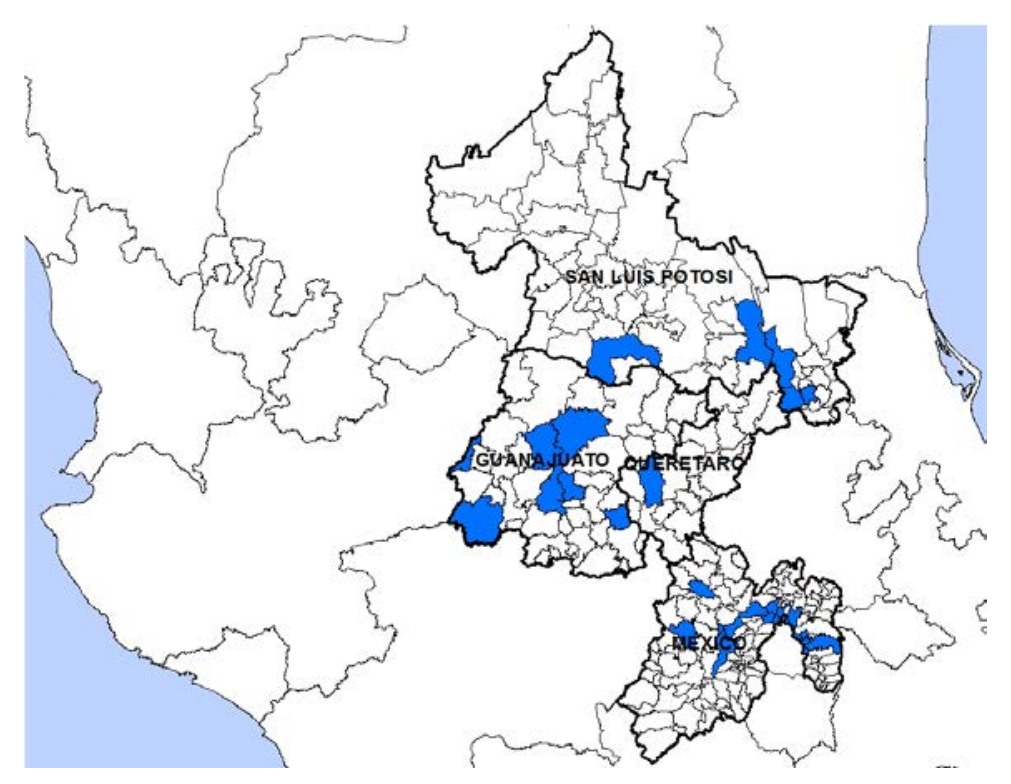

Figure 3: The 26 municipalities in our sample

chosen for security and logistical reasons, and because they exhibit variation in the municipal incumbent party. The 26 municipalities were selected from the 56 municipalities in these states in which an audit was released in 2015 according to three criteria. The first criteria relates to the safety of voters and our distribution and survey teams. This entailed eliminating 12 municipalities. Second, to ensure that there is variation in performance between incumbent and challenger parties, we only selected municipalities in which the ASF's audit revealed that at least one of the two measures of reported malfeasance (percentage of FISM funds not spent on the poor or spent on unauthorized projects) was at least two percentage points lower (or, more often, higher) than the state average of opposition parties. This excluded three of the remaining audited municipalities. Of the 41 left, we selected municipalities to match the distribution of incumbent parties across audited municipal governments in these four states. ${ }^{19}$

After immediately receiving threats upon entering Aquismón and Villa Victoria, these municipalities were replaced by Atlacomulco, Temoaya, and an additional block from Tlalnepantla de Baz in the state of México. Importantly, since our blocking strategy — explained in detail belowensures that all blocks are contained within the same municipality, excluding these problematic municipalities does not affect the study's internal validity.

\footnotetext{
${ }^{19}$ Of our 26 municipalities, 17 were governed by the PRI (including 16 in coalition with the Teacher's (PNA) and Green (PVEM) parties), five by the PAN (including two in coalition with the PNA), two by the $\mathrm{PRD}$, and one by the Citizen's Movement (MC).
} 
Within each municipality, we selected up to one-third of the electoral precincts. To generate variation in the level of malfeasance reported, we oversampled precincts from municipalities with particularly high or low levels of incumbent malfeasance and starker contrasts with opposition party malfeasance within the state. Within municipalities, we first prioritized accessible rural precincts, where possible, in order to minimize cross-precinct spillovers and maximize the probability that voters would not receive the audit information through other means. Moreover, to maximize the share of households that we could reach with a fixed number of leaflets, attention was restricted to precincts with fewer registered voters. In urban areas, where we had more precincts to choose from, we restricted our sample to precincts with at most 1,750 registered voters, and designed an algorithm to minimize the number of neighboring urban precincts in our sample. ${ }^{20}$ Ultimately, rural precincts represent $51 \%$ of our sample. More generally, Appendix Table A1 shows that our final sample of precincts is similar to the national distribution according to various socioeconomic indicators from the 2010 Census.

\subsection{Information treatment}

In partnership with the non-partisan Mexican NGO Borde Político, ${ }^{21}$ we sought to evaluate the impact of distributing leaflets to voters that documented the use of FISM funds in their municipality. For each municipality, the leaflet focused on either the proportion of unauthorized spending or spending that did not benefit the poor (but never on both in the same municipality). For each municipality, we chose the malfeasance measure that maximized the difference from other parties within the municipality's state. All treatments were delivered at the electoral precinct level, Mexico's lowest level of electoral aggregation.

Our leaflet was designed to be non-partisan, accessible, and sufficiently intriguing that voters would not discard it. ${ }^{22}$ Figure 4 provides an example of a leaflet focusing on a severe case of unauthorized spending in the municipality of Ecatepec de Morelos in the state of México. The front page explains that Borde Político is a non-partisan organization and that the information

\footnotetext{
${ }^{20}$ The algorithm started with the set of neighboring precincts surrounding each precinct and identified all neighboring precincts that were eligible for our sample; we then iteratively removed the precinct with the most "in-sample" neighbors until we reached the required number of precincts for that municipality. In most municipalities, the algorithm ensured that our sample contained no neighboring precincts.

${ }^{21}$ Borde Político is a leading NGO seeking to increase voter knowledge about the actions of their politicians in office, with significant experience in developing web-based platforms to provide politically relevant information to voters (see borde.mx).

${ }^{22}$ It was produced by a local graphic designer based on feedback from multiple focus groups. We also sought legal advice to ensure that our leaflets did not constitute political advertisements, and thus were not subject to distribution restrictions stipulated in Mexican electoral law.
} 


\section{ETy:}

FONDO DE INFRAESTRUCTURA

SOCIAL MUNICIPAL, DEBE

GASTARSE EN OBRAS DE

INFRAESTRUCTURA

LOS GASTOS QUE NO SEAN EN OBRAS DE INFRAESTRUCTURA DEBEN SER O\%

iBORDE ES UNA ASOCIACIÓN CIVIL

SIN FINES PARTIDISTAS

INFORMACIÓN

IMPORTANTE!

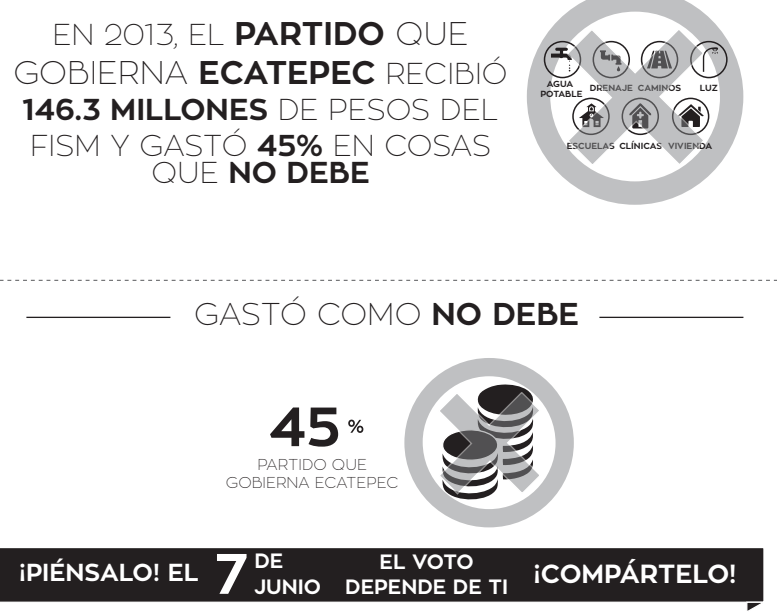

Figure 4: Example of local information leaflet in Ecatepec de Morelos, México

contained in the leaflet is based on the ASF's official audit reports, which are available online. The main page first states that FISM funds should only be spent on social infrastructure projects, and provides examples of such projects on the right. The leaflet then informs recipients of the total amount of money their municipality received (146.3 million pesos, in this case), and the percentage of this money spent in an unauthorized way by their government (45\%). To avoid suspicions of political motivation, neither the incumbent mayor nor their party is referred to directly, although as noted above the vast majority of voters could correctly identify the party of their incumbent mayor. Appendix Figure A2 provides an example from the municipality of Salamanca in Guanajuato, where all 54.1 million pesos were correctly allocated to social infrastructure projects that benefited the poor. More generally, Figure 5 shows that the average precinct in our sample was informed of $21 \%$ malfeasant spending within their municipality.

Although they are not the main focus of this article, the experiment also incorporated two variants of this information treatment. First, to examine the effect of providing voters with a bench- 


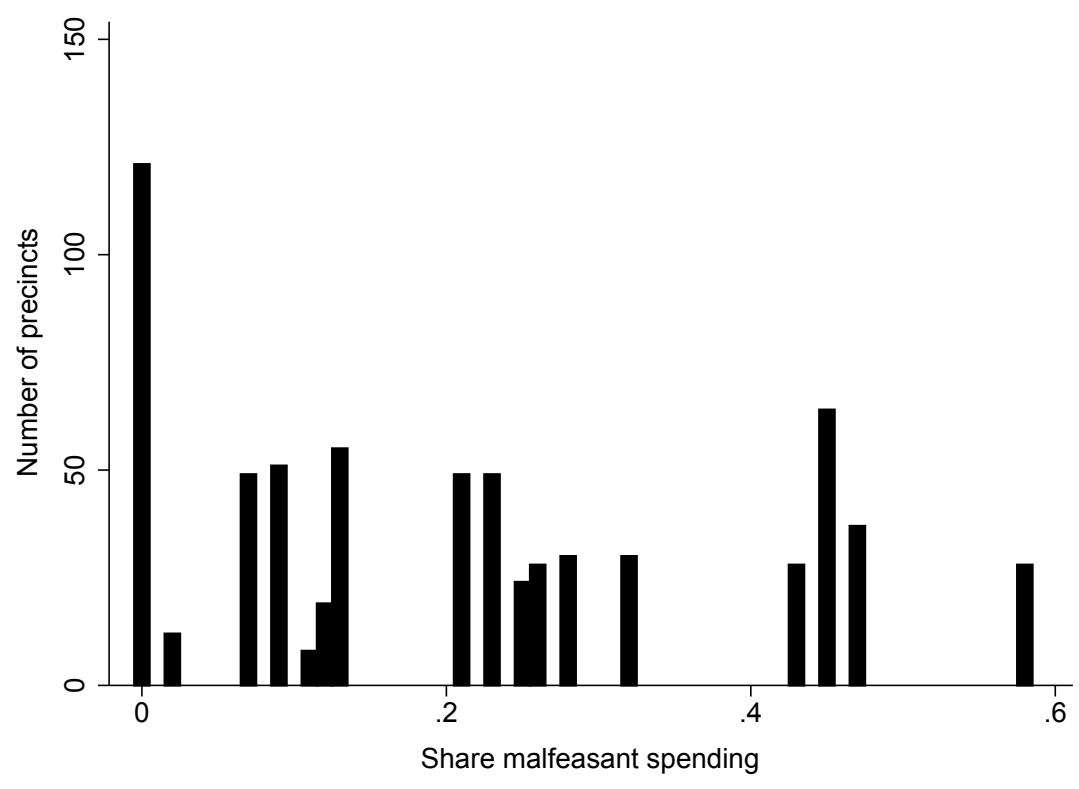

Figure 5: Precincts by share of malfeasant spending in our sample

mark against which to compare their municipality's malfeasance, we supplemented the leaflet by providing the mean outcome among all audited municipalities within the same state governed by a different political party. Second, to vary the extent to which the distribution of the leaflets is common knowledge among voters within the precinct, we also varied whether leaflet delivery was accompanied by a loudspeaker informing voters that their neighbors would also receive the information and encouraging them to share and discuss it. These treatment variants did not generate different effects, as shown in Table A21. We present more details about the treatment variants and additional results in a short companion paper (Arias et al. 2018).

\subsection{Block randomization and implementation}

Our sample of 678 precincts was allocated according to the factorial design, with a pure control, shown in Table 1 . The 400 treated precincts were equally divided between the four variants of the information treatment. Given that neither the comparative nor public information variants significantly moderated our treatment effects, and all leaflets contained the same baseline information pertaining to incumbent malfeasance, we proceed by pooling all treatment conditions. The control group comprising 278 electoral precincts reflects our sampling and block randomization design.

For the randomization, precincts were first stratified into rural or urban blocks containing six 
Table 1: Factorial design with a pure control

\begin{tabular}{l|ccc} 
& Control & Private & Public \\
\hline Control & 278 precincts & \\
Local & & 100 precincts & 100 precincts \\
Comparative & & 100 precincts & 100 precincts
\end{tabular}

or seven similar precincts within a given municipality. ${ }^{23}$ Precinct similarity was defined by the Mahalanobis distance between 23 social, economic, demographic, and political variables provided by Mexico's National Statistical Agency and the National Electoral Institute (INE) ${ }^{24}$ Within each block, we then randomly assigned precincts to each of the treatment conditions and, depending on the availability of an additional precinct, either two or three pure control precincts. Block randomization increases the power of the experiment by minimizing differences between treated and control precincts. Because blocks lie strictly within municipalities, malfeasance information pertains to the same municipal incumbent party for all precincts within a block.

The leaflets were distributed by our implementing partners Data OPM and Qué Funciona para el Desarollo using precinct maps provided by the INE. Our distribution teams delivered one leaflet to a maximum of 200 randomly selected households in the largest locality (in rural blocks) and randomly selected city blocks (in urban blocks) within each treated precinct. ${ }^{25}$ Within our sample, the median precinct contained 353 households (according to the 2010 Census), 420 private dwellings, and 1,056 voters registered for the 2015 election. Where possible, leaflets were delivered in person with a short verbal explanation of the leaflet's provenance. When no adult was available, leaflets were left in mailboxes or taped to the recipient's front door in a waterproof bag. Leaflet delivery took several hours per precinct, and was conducted over a period of three weeks, concluding at the legally designated end of the election campaign four days before the election. Our team recorded where leaflets were distributed in order to return for the post-election follow-up survey.

While compliance with the delivery of our treatments was very good in general, we nevertheless encountered some issues in the field. In a couple of cases, some leaflets were delivered to voters outside the precinct or adverse weather conditions and poor road conditions prevented us from

\footnotetext{
${ }^{23}$ If there were sufficient precincts, and the total treated precincts did not exceed one-third of all precincts, we used blocks of seven precincts.

${ }^{24}$ We used the R package blockTools to assign precincts to blocks. The algorithm is "greedy" in that it creates the most similar group first. Where a surplus of potential precincts was available, we used the most similar blocks to maximize statistical efficiency.

${ }^{25}$ Since randomization blocks consist of either only rural or only urban precincts, block fixed effects fully account for any sampling differences across rural and urban precincts.
} 
reaching a precinct. ${ }^{26}$ To preserve the randomization, we focus on estimating intent to treat (ITT) effects, which are arguably the most policy relevant.

\subsection{Precinct- and individual-level data}

We collected two sources of data to measure our main outcomes. First, by combining publicly available results and freedom of information requests, we collected official precinct-level electoral returns from each state's electoral institute. We use this data to measure our three pre-registered precinct-level outcomes: incumbent party vote share (as a share of turnout), incumbent party vote share (as a share of registered voters), and turnout. Measuring incumbent party vote share using the share of registered voters allows us to abstract from changes in turnout. We drop the three precincts in our sample that were merged with another precinct because they contained fewer than 100 registered voters, which produces a final sample of 675 electoral precincts. ${ }^{27}$ We complement the 2015 precinct-level electoral returns with the background covariates from the 2010 Census and 2012 electoral returns that we used for our block randomization.

Second, we conducted a post-election survey: we interviewed 10 voters from each of the treated precincts and 10 voters from a randomly selected control precinct within each block. ${ }^{28}$ Most importantly, at the beginning of the survey we measured voters' posterior beliefs about incumbent malfeasance (i.e. $\theta_{I}$ in our model). Specifically, we asked respondents to rate, on a five-point scale from very low (-2) to very high (2), each major party's level of corruption or level of interest in supporting the poor (depending on the measure of malfeasance we focused on in that municipality). ${ }^{29}$ Higher values of this variable thus indicate that voters believed a party was more malfeasant (i.e. a higher $\mu_{I}$ in our model). ${ }^{30}$ To gauge the precision of these beliefs (i.e. $\lambda_{I}$ in our model), we then asked respondents to report how certain they were about this belief on a four-point scale from very uncertain (1) to very certain (4). Summary statistics for major variables are provided in

\footnotetext{
${ }^{26}$ The results are robust to dropping the misassigned precincts from our sample.

${ }^{27}$ In two of these cases, a small precinct was merged with another precinct that remains in our sample; where the treatment condition conflicts, we retain the larger precinct's treatment status. We were not aware of these merges when the experiment was designed.

${ }^{28}$ For treated precincts, enumerators were instructed to survey the localities and city blocks where our informational treatment was delivered. In control precincts, respondents were chosen according to the same protocol used to determine the delivery of leaflets in treated rural and urban blocks.

${ }^{29}$ We did not ask explicitly about the MC party, which was the incumbent party only in Apaseo el Alto. Consequently, the 24 precincts from this municipality are dropped from analyses examining prior beliefs.

${ }^{30} \mathrm{We}$ did not elicit perceptions regarding the exact share of funds that respondents believe each party spends in a malfeasant way, as this would have been hard to assess for our sample of mostly uneducated voters.
} 
Appendix Table A2.

\subsection{Estimation and balance}

Following our pre-analysis plan, we estimate the average ITT effect of providing any type of information using OLS regressions of the form:

$$
Y_{p b m}=\text { RTreatment }_{p b m}+\eta_{b m}+\varepsilon_{p b m}
$$

where $Y_{p b m}$ is an outcome for electoral precinct $p$ within randomization block $b$ in municipality $m$. For individual-level survey outcomes, $Y_{i p b m}$ also includes an $i$ subscript. Block fixed effects, $\eta_{b m}$, are included to adjust for the differential treatment probabilities across blocks arising from different block sizes. Moreover, block fixed effects increase efficiency by enabling us to fully control for all block-specific characteristics, including race-specific differences across municipalities. Importantly, including block fixed effects ensures that we only compare precincts that chose between the same candidates. Throughout, standard errors are clustered at the municipality-treatment level. ${ }^{31}$

We weight precinct-level observations by the share of voters to whom we delivered a leaflet. In control precincts, we use the share of leaflets delivered to the average treated precinct within a block. This weighting scheme - the only departure from our pre-registered specifications_-permits more precise estimates by de-weighting large precincts in which only a small fraction of voters could receive the leaflet. Nevertheless, we show similar results weighting each precinct equally as a robustness check in Table 6 below. In treated precincts, we only interviewed voters that were delivered leaflets; thus individual-level observations remain unweighted. ${ }^{32}$

Our main estimates pool municipalities that received information about unauthorized spending and spending on projects that did not benefit the poor. If voters evaluate these dimensions of malfeasance similarly, this maximizes the power of the experimental design. Since voters could plausibly respond to negligent and corrupt spending differently, we also examine these types of information separately in Table A17 and observe similar responses.

We use the baseline specification to validate the randomization. Appendix Table A3 demonstrates that the treatment is well balanced across 46 precinct and survey respondent characteristics. As usual, there are some significant differences, most notably with respect to incumbent vote share in the previous elections in 2012. In Table 6 we demonstrate that the results are robust-and,

\footnotetext{
${ }^{31}$ We pre-specified that standard errors would be clustered at the municipality-treatment level in order to account for the non-independence of responses to the same treatment condition within a municipality.

${ }^{32}$ Predicting the likelihood that respondents reported receiving the leaflet, we find no significant interaction between the treatment and the share of voters in the precinct that could be treated.
} 
if anything, more precisely estimated-when we control for the 40 precinct-level pre-treatment variables.

\subsection{Heterogeneous effects}

We expect our informational treatment to have different effects across different types of voters. For example, it is not obvious whether misallocated spending totaling $10 \%$ represents good or bad news without comparing information content with voters' prior expectations. To test our hypotheses examining how the effects of providing malfeasance information vary with voters' prior beliefs, signal content, and the direction of voter updating, we estimate interactive specifications of the form:

$$
Y_{p b m}=\beta_{\text {Treatment }_{p b m}}+\gamma\left(\text { Treatment }_{p b m} \times X_{m}\right)+\eta_{b m}+\varepsilon_{p b m}
$$

where $X_{m}$ is a municipality-level measure capturing the heterogeneous effects implied by hypotheses H1-H3. Since $X_{m}$ is not randomly assigned, we also show the robustness of these specifications to interacting our treatment with potential confounders of $X_{m}$.

Measuring the prior beliefs and voter updating required to test parts of $\mathrm{H} 1$ and $\mathrm{H} 2$ is challenging in our context. Given that we were not able to conduct a baseline survey due to financial constraints, we use the post-election responses from each municipality's surveyed control precincts to proxy for the average pre-treatment beliefs of the treated and control voters within the same municipality. Specifically, to measure the level of voters' prior beliefs-a proxy for the parameter $\mu_{I}$ in the model-we use the mean belief about the incumbent party's malfeasance reported in a municipality's control group. For the precision of such prior beliefs (parameter $\lambda_{I}$ ), we similarly use the mean precision of the incumbent malfeasance perceptions reported in a municipality's control group.

To proxy for voter updating in a given municipality, we measure the extent to which the treatment caused control voters to update their posterior beliefs about the incumbent party's malfeasance. Specifically, at the end of the survey we showed all voters the leaflet corresponding to their municipality and asked them again how they perceived the incumbent party on the same five-point scale. To capture the extent to which voters in each municipality updated their prior beliefs about the incumbent party, we simply consider the average change in perceptions before and after showing the corresponding leaflets to voters in a municipality's control precincts. This approximates $\Delta_{I}$ in our model, where positive (negative) values imply that the voters' posterior assessment is worse (better) than their prior beliefs (i.e. unfavorable updating about the incumbent). Given that 
control group voters in the survey had less time to internalize the information than those in treated precincts, we focus on the slope with respect to updating, rather than relying on the the levels of updating to categorize favorable and unfavorable updating.

Using post-election surveys from the control group to proxy for pre-treatment beliefs requires two assumptions: (1) that control group respondents are similar to treatment group respondents and (2) that control group respondent beliefs are consistent across the month between the intervention and the post-election survey. Appendix section A.3.3 provides extensive support for these assumptions. In short, our randomization and the lack of selection into the endline sample support assumption (1), while our blocking strategy ensures that treated and control respondents within municipalities are similar in practice. In support of assumption (2), we show that municipal-level electoral outcomes do not influence control group beliefs, that there is no evidence of cross-precinct spillovers, that control group respondents update more than treated respondents upon being shown the leaflet, and that a validation exercise we conducted using a panel survey in Brazil suggests limited changes in politician assessments just before and after elections among control voters.

\section{How do voters interpret the information treatment?}

Before examining the precinct-level electoral results, we first assess how the information treatment affected voters' actions and posterior beliefs using our post-election survey.

\subsection{Manipulation checks}

We first conduct several "manipulation checks" to ensure that treated voters indeed experienced the treatment as intended. The four self-reported outcomes in Table 2 provide clear evidence that voters received and engaged with the information distributed. Column (1) demonstrates that treated voters are 25 percentage points more likely to report remembering receiving our leaflet, relative to a control mean of $9 \%$ of voters. ${ }^{33}$ Moreover, column (2) confirms that voters in treated precincts were 17 percentage points more likely to report having read the leaflet, while column (3) shows that treated voters were 14 percentage points more likely to correctly recall the issue covered in the leaflet. ${ }^{34}$ Given that voters may only hazily recall receiving a specific pamphlet around the

\footnotetext{
${ }^{33}$ The non-zero control mean likely reflects respondents mistaking our leaflet for another leaflet. As noted above, Appendix Tables A5 and A6 provide little evidence to suggest that there were cross-precinct spillovers.

${ }^{34}$ In addition to both types of spending, respondents were also given the opportunity to say that the leaflet contained unemployment or public security information.
} 
Table 2: Effect of information treatment on self-reported engagement with leaflet

\begin{tabular}{lcccc}
\hline & $\begin{array}{c}\text { Remember } \\
\text { leaflet }\end{array}$ & $\begin{array}{c}\text { Remember } \\
\text { reading } \\
\text { leaflet } \\
(1)\end{array}$ & $\begin{array}{c}\text { Correctly } \\
\text { remember } \\
\text { content } \\
(3)\end{array}$ & $\begin{array}{c}\text { Leaflet } \\
\text { influenced } \\
\text { vote } \\
(4)\end{array}$ \\
\hline Information treatment & $0.247^{* * *}$ & $0.171^{* * *}$ & $0.138^{* * *}$ & $0.051^{* * *}$ \\
& $(0.022)$ & $(0.018)$ & $(0.019)$ & $(0.010)$ \\
Outcome range & $\{0,1\}$ & $\{0,1\}$ & $\{0,1\}$ & $\{0,1\}$ \\
Control outcome mean & 0.09 & 0.05 & 0.06 & 0.02 \\
Control outcome std. dev. & 0.28 & 0.22 & 0.25 & 0.14 \\
$R^{2}$ & 0.11 & 0.09 & 0.10 & 0.06 \\
Observations & 4,958 & 4,958 & 4,958 & 4,958 \\
\hline
\end{tabular}

Notes: All specifications include block fixed effects, and are estimated using OLS. Standard errors clustered by municipality-treatment are in parentheses. * denotes $p<0.1$, ** denotes $p<0.05$, *** denotes $p<0.01$.

election, these differences are likely to be lower bounds. Finally, column (4) indicates that $7 \%$ of treated voters reported that the leaflet influenced their vote choice, which is 5 percentage points higher than for voters located in control precincts.

Voters generally did not believe that the leaflet was politically motivated. Among treated precincts, $44 \%$ of voters believed that the leaflet came from a non-partisan NGO. This response was more than twice as likely as any particular political party, while $33 \%$ did not know. The difference was even greater among those who remembered the leaflet. Moreover, neither the comparative nor public treatment variants—which could have been perceived as more political—differentially affected the perception that the treatment emanated from a government or political source. Finally, such perceptions about the leaflet are not correlated with municipal-level prior beliefs, the precision of those beliefs, or belief updating. These results are reported in Appendix Tables A9 and A10.

\subsection{The effect of information on voters' posterior beliefs}

The distribution of prior beliefs about the municipal incumbent party's malfeasance in the control group indicates that voters had low expectations of incumbent parties. Figure 6 shows that most respondents are likely to report that the incumbent party engages in medium to very high levels of corruption or misallocated spending. Voters thus expected incumbent mayors to engage in non- 


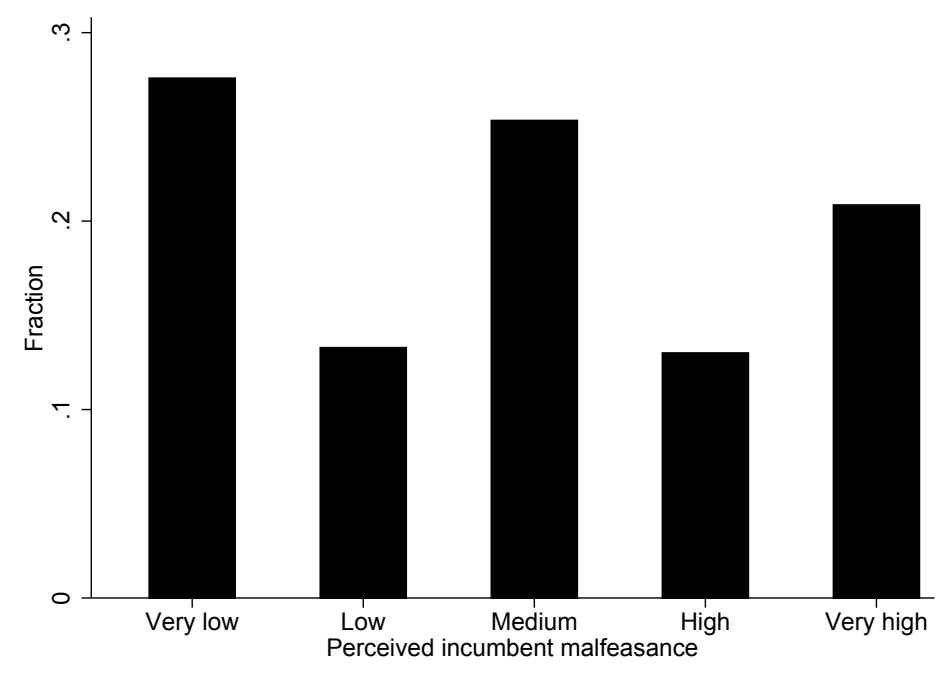

Figure 6: Perceived incumbent party malfeasance in control precincts

trivial levels of malfeasance in office, which is consistent with the prior beliefs of Mexican voters reported in Chong et al. (2015). Interestingly, there is considerable variation both within and across municipalities, but prior beliefs are not significantly correlated with the malfeasance levels documented in the ASF reports.

In such a context of low expectations of politicians, to understand how our information treatment will affect incumbent party support on average, it is essential to understand whether voters favorably or unfavorably update their posterior beliefs about the incumbent party's malfeasance. In particular, we estimate equations (4) and (5) to examine how the treatment affected the posterior beliefs of treated voters regarding the incumbent party's level of malfeasance. The negative, albeit far from statistically significant, coefficient in column (1) of Table 3 shows that treated voters did not increase their posterior beliefs about their incumbent party's malfeasance upon learning of relatively high levels of malfeasance, on average. As in Banerjee et al. (2011), this finding suggests that the information provided broadly aligned with what voters already believed.

However, the lack of updating among treated voters on average masks substantial heterogeneity in responses across voters who have different prior beliefs. Consistent with hypothesis H1, the treatment's interaction with voters' prior beliefs in column (2) indicates that treated voters within municipalities that have unfavorable prior beliefs (i.e. pre-existing expectations of high levels of malfeasance) about the incumbent favorably update those beliefs about the incumbent, while treated voters with favorable prior beliefs (i.e. expectations of low malfeasance) are more likely to report perceiving their incumbent as corrupt or neglectful of the poor. Appendix Table 
Table 3: Effect of information treatment on voters' posterior beliefs about incumbent party malfeasance

\begin{tabular}{|c|c|c|c|c|c|}
\hline & \multicolumn{5}{|c|}{ Perceived incumbent party malfeasance (very low to very high) } \\
\hline & (1) & (2) & (3) & (4) & (5) \\
\hline Information treatment & -0.001 & -0.015 & 0.427 & 0.016 & $-0.096 * *$ \\
\hline & $(0.040)$ & $(0.037)$ & $(0.476)$ & $(0.067)$ & $(0.047)$ \\
\hline$\times$ Incumbent malfeasance prior & & $\begin{array}{c}-0.126 * * * \\
(0.035)\end{array}$ & & & \\
\hline$\times$ Incumbent prior precision & & & $\begin{array}{l}-0.132 \\
(0.149)\end{array}$ & & \\
\hline$\times$ Incumbent malfeasant spending & & & & $\begin{array}{l}-0.083 \\
(0.214)\end{array}$ & \\
\hline$\times$ Unfavorable incumbent updating & & & & & $\begin{array}{c}0.102 * * * \\
(0.030)\end{array}$ \\
\hline Outcome range & $\{-2,-1,0,1,2\}$ & $\{-2,-1,0,1,2\}$ & $\{-2,-1,0,1,2\}$ & $\{-2,-1,0,1,2\}$ & $\{-2,-1,0,1,2\}$ \\
\hline Control outcome mean & -0.14 & -0.14 & -0.14 & -0.14 & -0.14 \\
\hline Control outcome std. dev. & 1.48 & 1.48 & 1.48 & 1.48 & 1.48 \\
\hline Interaction range & & {$[-1.4,1.1]$} & {$[2.4,3.8]$} & {$[0,0.58]$} & {$[-0.6,2.7]$} \\
\hline Interaction mean & & -0.09 & 3.23 & 0.21 & 0.91 \\
\hline Interaction std. dev. & & 0.82 & 0.26 & 0.17 & 1.00 \\
\hline$R^{2}$ & 0.29 & 0.29 & 0.29 & 0.29 & 0.29 \\
\hline Observations & 4,624 & 4,624 & 4,624 & 4,624 & 4,624 \\
\hline
\end{tabular}

Notes: All specifications include block fixed effects, and are estimated using OLS. Lower-order interaction terms are absorbed by the block fixed effects. Standard errors clustered by municipality-treatment are in parentheses. * denotes $p<0.1$, ** denotes $p<0.05$, *** denotes $p<0.01$.

A19 shows that this finding is robust to splitting our sample between municipalities with aboveand below-median priors. ${ }^{35}$ For the average leaflet, the difference in responses to the treatment between those with the most favorable and most unfavorable prior beliefs is almost one third of a standard deviation in the posterior belief. Moreover, column (3) shows that treated voters within municipalities with relatively weak prior beliefs are not significantly more likely to unfavorably update their posterior beliefs about their incumbent party. Given the lack of an average treatment effect, this finding is also consistent with the model's prediction that the magnitude of the average effect only significantly varies with the precision of voters' prior beliefs when the magnitude of the average effect is not zero.

The insignificant interaction in column (4) initially provides surprisingly little evidence that the

\footnotetext{
${ }^{35}$ This check addresses the concern that the results mechanically reflect municipal-level incumbent malfeasance priors being almost-perfectly explained by a combination of block-level variation in control group outcomes in column (2). Because we pool a relatively large number of control respondents within most municipalities, this strategy is unlikely to reflect measurement error at the median cutpoint.
} 
share of misspent funds differentially influences the posterior beliefs of treated voters. However, the precinct-level electoral results described below strongly support this hypothesis. Moreover, this changes once we account for how the information provided relates to prior beliefs. Supporting $\mathrm{H} 1$, the large and statistically significant positive coefficient on the interaction between the treatment indicator and our measure of voter updating in column (5) demonstrates that treated voters in municipalities where voters unfavorably (favorably) update their posterior beliefs about the incumbent display substantially more unfavorable (favorable) opinions of the incumbent party. Substantively, a one-standard-deviation difference in updating translates to around a 0.1-standarddeviation change in posterior beliefs among treated voters. ${ }^{36}$

Our information treatment could, in theory, also affect posterior beliefs about challengers (e.g. Kendall, Nannicini and Trebbi 2015). Appendix Tables A11-A13 show that treated voters with unfavorable prior beliefs about the challenger are also more likely to favorably update their posterior beliefs about the main challenger's malfeasance. Given that such effects are similar across the local and comparative variants of the treatment (Arias et al. 2018), this suggests that voters in our sample are primarily updating their posterior beliefs about challengers from the information they receive about the incumbent. This implies that voters believe that incumbents' and challengers' types are positively correlated. ${ }^{37}$ To the extent that voters updated similarly about challengers, our estimates are likely to understate the effect of information only inducing voters to update about the incumbent party. However, justifying our focus on incumbent parties, Tables A14-A16 show that voting behavior is driven primarily by how the treatment relates to voters' prior beliefs about the incumbent party rather than challenger parties. Appendix Section A.4 discusses these results in greater detail.

Together, these results confirm that voters meaningfully updated their posterior beliefs about the incumbent party in response to our information treatment. Moreover, the direction of updating varies substantially across voters, depending on how the information received relates to prior beliefs. We next examine whether voter updating translates into precinct-level vote choices.

\footnotetext{
${ }^{36}$ This result is not mechanical, since municipal-level measures of unfavorable updating are based only on responses from voters in control precincts upon receiving the leaflet.

${ }^{37}$ On 5-point scales of perceived similarity of candidates across parties, ranging from not all probable to extremely probable that they will behave similarly in office, there is a 0.57 correlation in the control group. Similarly, conditional on believing that the incumbent is at least somewhat malfeasant, $69 \%$ of control group voters believe that challengers are also somewhat malfeasant.
} 


\section{Precinct-level election results}

We now present our three main precinct-level findings. First, reflecting a combination of voters' low expectations, as well as uncertainty-reduction and potentially differentially effective incumbent responses, the information treatment increases the incumbent's vote share, on average. Second, and consistent with our theoretical model, this effect is greatest where voters updated their posterior beliefs about the incumbent party most favorably based on the information received. Third, we identify a non-linear effect of information on electoral turnout such that intermediate levels of malfeasance reduce turnout, but extreme levels-either high or low-increase turnout.

\subsection{Average effects of information on incumbent vote share}

We first examine the average ITT effect of disseminating information about incumbents' malfeasance across our sample. We find that the information treatment increases the incumbent party's vote share, on average. Column (1) of panel A in Table 4 demonstrates that our intervention significantly increased the incumbent party's vote share, as a proportion of those that turned out, by an average of 2.6 percentage points. Column (1) of panel B similarly shows that this translates into a 1.3-percentage-point increase in the incumbent party's vote share, as a proportion of all registered voters in the precinct. The latter finding indicates that the information caused the incumbent to gain more voters, rather than simply demobilize challenger supporters. Relative to the mean vote share in the control group, the information treatment increased the incumbent party's vote share by $7 \%$, or around a quarter of a standard deviation. Moreover, the electoral results are broadly in line with the $5 \%$ of respondents - shown in Table 2-that claimed receiving the leaflet influenced their vote choice, given that only around $60 \%$ of households in the average precinct received a leaflet. ${ }^{38}$

Although voters' expectations were sufficiently low that malfeasance revelations did not shift their posterior beliefs on average, our model suggests that the incumbent party's vote share could increase due to the reduction in uncertainty associated with receiving information consistent with existing prior beliefs (see also Kendall, Nannicini and Trebbi 2015). This is captured by the $\frac{1}{2\left(\lambda_{I}+\rho_{I}\right)}$ term in equation (3).

We find evidence consistent with this risk-reduction interpretation in Table 5. While the average effect of providing information on posteriors' precision reported in column (1) is zero-likely due to a ceiling effect on high reported levels of precision (mean precision was 3.25 on the four-point scale in control precincts)_column (2) intuitively shows that the greatest increases in precision

\footnotetext{
${ }^{38}$ The survey may nevertheless underestimate the extent to which the same treatment induced some voters to change in different directions.
} 
Table 4: Effect of information treatment on incumbent party vote share

\begin{tabular}{|c|c|c|c|c|c|}
\hline & \multicolumn{5}{|c|}{ Incumbent party vote share } \\
\hline & (1) & (2) & (3) & (4) & $(5)$ \\
\hline \multicolumn{6}{|c|}{ Panel A: Incumbent party vote share (share of turnout) } \\
\hline Information treatment & $\begin{array}{c}0.026 * * * \\
(0.006)\end{array}$ & $\begin{array}{c}0.024 * * * \\
(0.005)\end{array}$ & $\begin{array}{c}0.168 * * * \\
(0.062)\end{array}$ & $\begin{array}{c}0.042 * * * \\
(0.007)\end{array}$ & $\begin{array}{c}0.034 * * * \\
(0.006)\end{array}$ \\
\hline$\times$ Incumbent malfeasance prior & & $\begin{array}{c}0.012 * * \\
(0.006)\end{array}$ & & & \\
\hline$\times$ Incumbent prior precision & & & $\begin{array}{c}-0.045^{* *} \\
(0.019)\end{array}$ & & \\
\hline$\times$ Incumbent malfeasant spending & & & & $\begin{array}{c}-0.072 * * * \\
(0.027)\end{array}$ & \\
\hline$\times$ Unfavorable incumbent updating & & & & & $\begin{array}{c}-0.012 * * \\
(0.004)\end{array}$ \\
\hline Outcome range & {$[0.07,0.85]$} & {$[0.07,0.85]$} & {$[0.07,0.85]$} & {$[0.07,0.85]$} & {$[0.07,0.85]$} \\
\hline Control outcome mean & 0.38 & 0.38 & 0.38 & 0.38 & 0.38 \\
\hline Control outcome std. dev. & 0.12 & 0.12 & 0.12 & 0.12 & 0.12 \\
\hline$R^{2}$ & 0.61 & 0.60 & 0.60 & 0.62 & 0.60 \\
\hline \multicolumn{6}{|c|}{ Panel B: Incumbent party vote share (share of registered voters) } \\
\hline Information treatment & $\begin{array}{c}0.013 * * * \\
(0.003)\end{array}$ & $\begin{array}{c}0.012 * * * \\
(0.003)\end{array}$ & $\begin{array}{c}0.084 * * \\
(0.035)\end{array}$ & $\begin{array}{c}0.022 * * * \\
(0.004)\end{array}$ & $\begin{array}{c}0.018 * * * \\
(0.003)\end{array}$ \\
\hline$\times$ Incumbent malfeasance prior & & $\begin{array}{c}0.007 * * * \\
(0.002)\end{array}$ & & & \\
\hline$\times$ Incumbent prior precision & & & $\begin{array}{c}-0.022 * * \\
(0.011)\end{array}$ & & \\
\hline$\times$ Incumbent malfeasant spending & & & & $\begin{array}{c}-0.043 * * * \\
(0.015)\end{array}$ & \\
\hline$\times$ Unfavorable incumbent updating & & & & & $\begin{array}{c}-0.007 * * * \\
(0.002)\end{array}$ \\
\hline Outcome range & {$[0.03,0.47]$} & {$[0.03,0.47]$} & {$[0.03,0.47]$} & {$[0.03,0.47]$} & {$[0.03,0.47]$} \\
\hline Control outcome mean & 0.19 & 0.19 & 0.19 & 0.19 & 0.19 \\
\hline Control outcome std. dev. & 0.07 & 0.07 & 0.07 & 0.07 & 0.07 \\
\hline$R^{2}$ & 0.64 & 0.64 & 0.63 & 0.64 & 0.64 \\
\hline Interaction range & & {$[-1.4,1.1]$} & {$[2.4,3.8]$} & {$[0,0.58]$} & {$[-0.6,2.7]$} \\
\hline Interaction mean & & -0.06 & 3.23 & 0.22 & 0.88 \\
\hline Interaction std. dev. & & 0.83 & 0.24 & 0.17 & 0.99 \\
\hline Observations & 675 & 651 & 651 & 675 & 651 \\
\hline
\end{tabular}

Notes: All specifications include block fixed effects, weight by the share of the precinct that was treated, and are estimated using OLS. Lower-order interaction terms are absorbed by the block fixed effects. The smaller sample in Columns (2), (3), and (5) reflect the lack of data on prior beliefs about the incumbent party in Apaseo el Alto. Standard errors clustered by municipality-treatment are in parentheses. $*$ denotes $p<0.1$, ** denotes $p<0.05$, *** denotes $p<0.01$. 
Table 5: Effect of information treatment on the precision of voters' posterior beliefs about incumbent party malfeasance

\begin{tabular}{|c|c|c|c|c|}
\hline & \multicolumn{4}{|c|}{$\begin{array}{l}\text { Precision of perceived incumbent party } \\
\text { malfeasance (very low - very high) }\end{array}$} \\
\hline & (1) & (2) & (3) & (4) \\
\hline & & & $\begin{array}{l}\text { Above-mean } \\
\text { incumbent } \\
\text { prior precision }\end{array}$ & $\begin{array}{l}\text { Below-mean } \\
\text { incumbent } \\
\text { prior precision }\end{array}$ \\
\hline \multirow[t]{2}{*}{ Information treatment } & 0.016 & $0.675 * *$ & -0.020 & $0.050 *$ \\
\hline & $(0.024)$ & $(0.265)$ & $(0.041)$ & $(0.026)$ \\
\hline \multirow[t]{2}{*}{$\times$ Incumbent prior precision } & & $-0.204 * *$ & & \\
\hline & & $(0.084)$ & & \\
\hline Outcome range & $\{1,2,3,4\}$ & $\{1,2,3,4\}$ & $\{1,2,3,4\}$ & $\{1,2,3,4\}$ \\
\hline Control outcome mean & 3.25 & 3.25 & 3.51 & 2.94 \\
\hline Control outcome std. dev. & 0.85 & 0.85 & 0.72 & 0.88 \\
\hline Interaction range & & {$[2.4,3.8]$} & & \\
\hline Interaction mean & & 3.23 & & \\
\hline Interaction std. dev. & & 0.26 & & \\
\hline$R^{2}$ & 0.11 & 0.11 & 0.06 & 0.06 \\
\hline Observations & 4,673 & 4,673 & 2,429 & 2,244 \\
\hline
\end{tabular}

Notes: All specifications include block fixed effects, and are estimated using OLS. Lower-order interaction terms are absorbed by the block fixed effects. Standard errors clustered by municipality-treatment are in parentheses. $*$ denotes $p<0.1$, ** denotes $p<0.05$, *** denotes $p<0.01$.

occur for respondents in municipalities with more imprecise prior beliefs. Reinforcing the interpretation that voters with the least precise prior beliefs updated most, the split-sample approach in columns (3) and (4) shows that there is a significant positive effect among respondents in municipalities with below-median prior precision (i.e. below 3.26) and, as anticipated, no detectable effect in municipalities where the precision of priors was greatest. ${ }^{39}$ This suggests that, given their low expectations of politicians, voters did not substantially improve their perception of incumbent party malfeasance, but nevertheless became more likely to vote for an incumbent party that represents a less risky option.

Another possible explanation is that voting behavior reflects general equilibrium considerations, including incumbent and challenger parties reactions to the information's provision. Table 8 below documents evidence indicating that both incumbent and challenger parties responded to

\footnotetext{
${ }^{39}$ As with column (2) of Table 3, the split sample approach also addresses the concern that a combination of block fixed effects perfectly explain control group responses.
} 
our intervention. Although they did so in roughly equal measure, the incumbent's resource advantage could make their responses substantially more effective (e.g. Cruz, Keefer and Labonne 2017), which could contribute to the average positive effect. Importantly, our evidence of voter learning - to which we soon turn—suggests that political responses cannot fully account for these heterogeneous effects.

Moreover, it is unlikely that the positive average effect reflects other potential explanations. One possibility is that voters (falsely) credit the incumbent party for attracting FISM resources to their municipality. However, we find little support for this interpretation in Appendix Table A23, which shows no heterogeneous effects by the quantity of FISM funds received by the municipality, in either absolute or per voter terms. Another possibility is that the intervention may have been perceived as a smear campaign against the incumbent party. However, as shown above, voters nevertheless updated their posterior beliefs and generally believed that the information came from a non-partisan source. Finally, it is possible that treatment alters the weight voters attach to different issues when deciding how to cast their ballot. However, Appendix Table A24 reports no evidence to suggest that a candidate's honesty or likelihood of addressing poverty became more important to voters as a consequence of treatment.

\subsection{Heterogeneous effects of information on incumbent vote share}

Although treated precincts somewhat surprisingly rewarded incumbent parties on average, we next demonstrate that voter responses on the margin vary with the content of the information received exactly as theorized, and in line with our survey data documenting changes in posterior beliefs.

First, supporting hypothesis H2, our information treatment's largest positive effects are in precincts where voters were initially most likely to believe that their incumbent was malfeasant. Across both panels in Table 4, column (2) shows that the increase in incumbent party vote share caused by our information treatment is significantly greater (smaller) in precincts within municipalities where the control group had more unfavorable (favorable) prior beliefs regarding the incumbent party's level of malfeasance. These results indicate that moving from the municipality with the most favorable prior beliefs about the incumbent party $(-1.4)$ to the municipality with the most unfavorable prior beliefs (1.1) increases the effect of providing information on the incumbent party's vote share from 0.7 to 3.7 percentage points, and the effect on the incumbent's share of registered votes from 0.0 to 2.0 percentage points. Also consistent with $\mathrm{H} 2$ and the risk-reduction explanation for the positive average effect on the incumbent's vote share, column (3) in panel A identifies a significantly smaller positive effect of the information in precincts where the municipality's control respondents had more precise prior beliefs. 

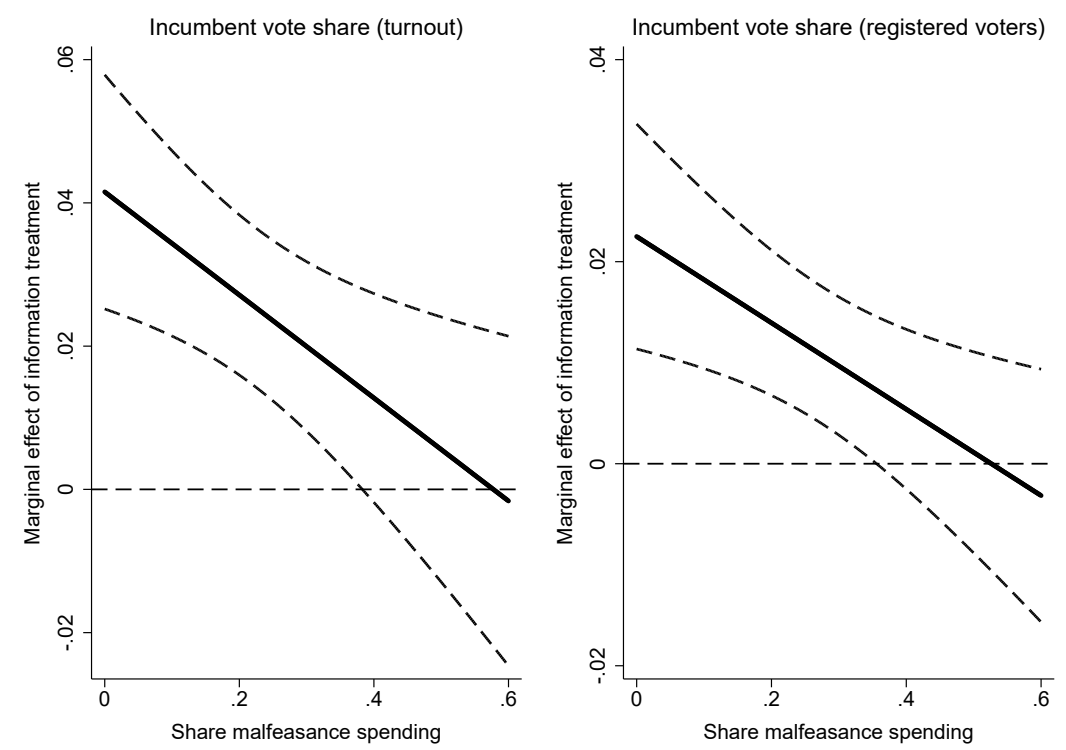

Figure 7: Marginal effect of information treatment on incumbent vote share, by share of malfeasant spending (95\% confidence intervals)

Second, and further supporting H2, the extent to which the incumbent party is rewarded declines with the level of malfeasance revealed to voters. The significant negative interaction in column (4) between the treatment and the share of malfeasant spending reported in the leaflet shows that voters reward incumbents for lower levels of malfeasance. As illustrated in Figure 7, revealing any level of malfeasant spending below $40 \%$ actually significantly increases the incumbent's vote share. Moreover, the effects are relatively substantial: a one-standard-deviation increase in reported malfeasance implies a 1.2-percentage-point decline in the incumbent party's vote share (as a share of turnout). The effect of providing information is never meaningfully negative in our sample, where the highest level of reported malfeasance is $58 \%$. However, among audit reports released between 2007 and 2015, 46 audited municipalities (3.4\% of all audited municipalities) across the country exceeded $60 \%$. As noted above, the level of rewards may also reflect the treatment reducing uncertainty about incumbent party malfeasance and eliciting political responses.

Third, and combining the preceding heterogeneous effects, the increase in incumbent party vote share caused by providing incumbent malfeasance information decreases with the extent to which the information causes voters to believe that the incumbent is more malfeasant than they previously believed. Column (5) of both panels demonstrates a significant negative interaction between the treatment and our measure of unfavorable updating of posterior beliefs in each munic- 
ipality's control precincts. A one-standard-deviation increase in unfavorable updating induced by the information treatment reduces the incumbent party's vote share (as a share of turnout) by 1.2 percentage points.

We find broadly similar results for revelations of information concerning spending that did not benefit the poor and unauthorized spending. Appendix Table A17 splits the sample between municipalities that received information about not spending FISM funds on projects that benefited the poor and spending on unauthorized projects. We again observe a clear positive average effect of our treatment across both types of malfeasant spending. Although the interactions with the share of malfeasant spending and the extent of unfavorable updating differ somewhat, the coefficients consistently point in the same direction across subsamples.

The lack of heterogeneity in electoral response by precinct socioeconomic developmentfound in unreported estimates - suggests that misallocating funds to projects that did not benefit the poor is no less salient where voters were less likely to directly benefit from FISM projects themselves. This suggests that voters, at least in our experimental sample, primarily worry about malfeasance in terms of incumbent integrity or competence, rather than its distributive implications.

\subsection{Robustness tests}

Table 6 demonstrates that the incumbent party vote share results are robust to several alternative specifications. While we focus on vote share as a share of actual turnout, Table A18 shows similar results for incumbent party vote share using registered voters-for which our results are generally stronger-in the denominator.

First, to address the potential concern that our results are driven by imbalances that remain after random assignment, panel A simultaneously controls for all 40 covariates we assess balance over. Unsurprisingly, the results are substantively indistinguishable and more precisely estimated.

Second, it is possible that our heterogeneous effects are confounded by correlates of voters' prior beliefs and municipal malfeasance. In particular, our estimates could be biased if voters' prior beliefs correlate with proxies for potential confounds relating to the extent of treatment dissemination, the ease with which our information treatment could be relayed through local networks, alternative sources of our information, and the level of political polarization. Accordingly, we control for the interaction of our information treatment with the following standardized covariates: share of the precinct electorate that received a leaflet, share that received a hand-delivered leaflet, distance to the municipality center, whether a precinct is rural, population density, number of radio and television stations covering the precinct that transmit from within the municipality, percentage 
Table 6: Robustness of information treatment on incumbent party vote share (share of turnout) Incumbent party vote share (share of turnout)

(1)

(2)

(3)

(4)

(5)

\begin{tabular}{|c|c|c|c|c|c|}
\hline \multicolumn{6}{|c|}{ Panel A: Controlling for 40 balancing covariates } \\
\hline Information treatment & $\begin{array}{c}0.019 * * * \\
(0.005)\end{array}$ & $\begin{array}{c}0.018 * * * \\
(0.005)\end{array}$ & $\begin{array}{c}0.132 * * \\
(0.055)\end{array}$ & $\begin{array}{c}0.038 * * * \\
(0.006)\end{array}$ & $\begin{array}{c}0.027 * * * \\
(0.006)\end{array}$ \\
\hline$\times$ Incumbent malfeasance prior & & $\begin{array}{l}0.009^{*} \\
(0.005)\end{array}$ & & & \\
\hline$\times$ Incumbent prior precision & & & $\begin{array}{c}-0.035^{* *} \\
(0.016)\end{array}$ & & \\
\hline$\times$ Incumbent malfeasant spending & & & & $\begin{array}{c}-0.090 * * * \\
(0.023)\end{array}$ & \\
\hline$\times$ Unfavorable incumbent updating & & & & & $\begin{array}{c}-0.011 * * * \\
(0.004)\end{array}$ \\
\hline \multicolumn{6}{|c|}{ Panel B: Controlling for standardized covariates interacted with information treatment } \\
\hline Information treatment & $\begin{array}{c}0.027 * * * \\
(0.005)\end{array}$ & $\begin{array}{c}0.026^{* * *} * \\
(0.005)\end{array}$ & $\begin{array}{c}-0.019 \\
(0.079)\end{array}$ & $\begin{array}{c}0.044 * * * \\
(0.007)\end{array}$ & $\begin{array}{c}0.038 * * * \\
(0.005)\end{array}$ \\
\hline$\times$ Incumbent malfeasance prior & & $\begin{array}{c}0.015 * * * \\
(0.005)\end{array}$ & & & \\
\hline$\times$ Incumbent prior precision & & & $\begin{array}{c}0.014 \\
(0.025)\end{array}$ & & \\
\hline$\times$ Incumbent malfeasant spending & & & & $\begin{array}{c}-0.082 * * \\
(0.034)\end{array}$ & \\
\hline$\times$ Unfavorable incumbent updating & & & & & $\begin{array}{c}-0.015 * * * \\
(0.003)\end{array}$ \\
\hline \multicolumn{6}{|c|}{ Panel C: Unweighted precinct estimates } \\
\hline Information treatment & $\begin{array}{c}0.020 * * * \\
(0.004)\end{array}$ & $\begin{array}{c}0.019 * * * \\
(0.004)\end{array}$ & $\begin{array}{c}0.146^{* * *} * \\
(0.044)\end{array}$ & $\begin{array}{c}0.031 * * * \\
(0.006)\end{array}$ & $\begin{array}{c}0.026 * * * \\
(0.004)\end{array}$ \\
\hline$\times$ Incumbent malfeasance prior & & $\begin{array}{l}0.009 * \\
(0.005)\end{array}$ & & & \\
\hline$\times$ Incumbent prior precision & & & $\begin{array}{c}-0.040 * * * \\
(0.014)\end{array}$ & & \\
\hline$\times$ Incumbent malfeasant spending & & & & $\begin{array}{c}-0.052 * * \\
(0.023)\end{array}$ & \\
\hline$\times$ Unfavorable incumbent updating & & & & & $\begin{array}{c}-0.009 * * \\
(0.004)\end{array}$ \\
\hline
\end{tabular}

Notes: All specifications include block fixed effects, weight by the share of the precinct that was treated (except those in panel C), and are estimated using OLS. See text for interacted controls included in panel B. Lower-order interaction terms are absorbed by the block fixed effects. Standard errors clustered by municipality-treatment are in parentheses. $*$ denotes $p<0.1, * *$ denotes $p<0.05, * * *$ denotes $p<0.01$. 
of households with access to a television, percentage of households with access to the internet, and municipal winning margin in the previous election. We purposely try to avoid controlling for variables that could determine voters' prior beliefs themselves, given that this would induce a contamination bias whereby our estimates could partial out the effects of the characteristics that drive prior beliefs.

The results in panel B demonstrate that our heterogeneous effects are generally robust, supporting our interpretation that voters respond to malfeasance revelations in a Bayesian manner. Only in the case of the interaction with the precision of prior beliefs are the results sensitive to the inclusion of interactive controls. Further analysis suggests that this sensitivity primarily reflects interactively controlling for our proxies for ruralness, which could be determinants of prior precision as well as information flows within voter networks.

In spite of the risk that controlling for determinants of priors could contaminate our estimates of heterogeneous effects by prior beliefs, Appendix Table A20 also demonstrates that our results are robust to controlling for further interactions with pre-treatment measures of economic development, education, and political engagement. This suggests that the differential effects that we attribute to voter learning are not instead driven by potential correlates of prior beliefs and the signal such as the capacity to comprehend the treatment or differential incidence of costs associated with malfeasance.

Third, despite increasing the weight on large precincts in which proportionately fewer voters were delivered the treatment, panel $\mathrm{C}$ shows that the results are robust to equally weighting all precincts.

\subsection{Non-linear effects of information on turnout}

A distinctive feature of our theory is the non-linear relationship between the extent of malfeasance and turnout. In particular, we predicted that revelations of either extremely low or high levels of malfeasance would induce voters to switch parties.

The results in Table 7 support this non-linear prediction. Providing evidence consistent with $\mathrm{H} 3$, column (3) shows that for very low levels of malfeasance, the lower-order treatment term indicates that turnout significantly increases by 1 percentage point, while the negative linear and positive quadratic interactions with the share of malfeasant spending demonstrate that turnout decreases for interim levels of malfeasance but increases for high levels of malfeasance. Figure 8 depicts this non-linearity graphically. In line with such heterogeneity in responses, column (1) shows that, on average, providing information does not affect turnout.

Column (4) shows that the results are robust to splitting the sample into quartiles by level 
Table 7: Effect of information treatment on turnout and confidence in the electoral process

\begin{tabular}{|c|c|c|c|c|c|}
\hline \multirow[t]{2}{*}{ Panel A: Turnout } & \multicolumn{4}{|c|}{ Turnout } & \\
\hline & (1) & (2) & (3) & (4) & \\
\hline Information treatment & $\begin{array}{l}-0.003 \\
(0.004)\end{array}$ & $\begin{array}{l}-0.003 \\
(0.006)\end{array}$ & $\begin{array}{l}0.010^{*} \\
(0.006)\end{array}$ & $\begin{array}{l}0.010^{*} \\
(0.006)\end{array}$ & \\
\hline$\times$ Incumbent malfeasance spending & & $\begin{array}{l}-0.001 \\
(0.018)\end{array}$ & $\begin{array}{l}-0.187 * * * \\
(0.057)\end{array}$ & & \\
\hline$\times$ Incumbent malfeasance spending squared & & & $\begin{array}{c}0.364 * * * \\
(0.108)\end{array}$ & & \\
\hline$\times$ Incumbent malfeasance spending quartile 2 & & & & $\begin{array}{l}-0.014 \\
(0.008)\end{array}$ & \\
\hline$\times$ Incumbent malfeasance spending quartile 3 & & & & $\begin{array}{l}-0.032 * * * \\
(0.008)\end{array}$ & \\
\hline$\times$ Incumbent malfeasance spending quartile 4 & & & & $\begin{array}{l}-0.000 \\
(0.006)\end{array}$ & \\
\hline Outcome range & {$[0.21,0.79]$} & {$[0.21,0.79]$} & {$[0.21,0.79]$} & {$[0.21,0.79]$} & \\
\hline Control outcome mean & 0.51 & 0.51 & 0.51 & 0.51 & \\
\hline Control outcome std. dev. & 0.10 & 0.10 & 0.10 & 0.10 & \\
\hline Interaction range & & {$[0,0.58]$} & {$[0,0.58]$} & & \\
\hline Interaction mean & & 0.22 & 0.22 & & \\
\hline Interaction std. dev. & & 0.17 & 0.17 & & \\
\hline$R^{2}$ & 0.70 & 0.70 & 0.70 & 0.70 & \\
\hline Observations & 675 & 675 & 675 & 675 & \\
\hline \multirow[t]{2}{*}{ Panel B: Confidence in the system } & \multicolumn{5}{|c|}{$\begin{array}{l}\text { Elections help to select competent candidates } \\
\text { (did not help at all - helped a lot) }\end{array}$} \\
\hline & (1) & (2) & (3) & (4) & $(5)$ \\
\hline Information treatment & $\begin{array}{c}0.008 \\
(0.042)\end{array}$ & $\begin{array}{l}-0.000 \\
(0.041)\end{array}$ & $\begin{array}{c}0.389 \\
(0.511)\end{array}$ & $\begin{array}{c}0.052 \\
(0.078)\end{array}$ & $\begin{array}{l}-0.044 \\
(0.054)\end{array}$ \\
\hline$\times$ Incumbent malfeasance prior & & $\begin{array}{l}-0.078 \\
(0.049)\end{array}$ & & & \\
\hline$\times$ Incumbent prior precision & & & $\begin{array}{l}-0.118 \\
(0.158)\end{array}$ & & \\
\hline$\times$ Incumbent malfeasant spending & & & & $\begin{array}{l}-0.209 \\
(0.255)\end{array}$ & \\
\hline$\times$ Unfavorable incumbent updating & & & & & $\begin{array}{c}0.057 \\
(0.038)\end{array}$ \\
\hline Outcome range & $\{1,2,3,4,5\}$ & $\{1,2,3,4,5\}$ & $\{1,2,3,4,5\}$ & $\{1,2,3,4,5\}$ & $\{1,2,3,4,5\}$ \\
\hline Control outcome mean & 2.86 & 2.86 & 2.84 & 2.86 & 2.86 \\
\hline Control outcome std. dev. & 1.40 & 1.40 & 1.41 & 1.40 & 1.40 \\
\hline Interaction range & & {$[-1.4,1.18]$} & {$[2.4,3.8]$} & {$[0,0.58]$} & {$[-0.6,2.7]$} \\
\hline Interaction mean & & -0.10 & 3.23 & 0.21 & 0.91 \\
\hline Interaction std. dev. & & 0.82 & 0.26 & 0.17 & 1.00 \\
\hline$R^{2}$ & 0.06 & 0.06 & 0.06 & 0.06 & 0.06 \\
\hline Observations & 4,615 & 4,615 & 4,615 & 4,615 & 4,615 \\
\hline
\end{tabular}

Notes: All specifications include block fixed effects, and are estimated using OLS. Panel A estimations are weighted by the share of the precinct that was treated. Lower-order interaction terms are absorbed by the block fixed effects. Standard errors clustered by municipality-treatment are in parentheses. $*$ denotes $p<0.1, * *$ denotes $p<0.05, * * *$ denotes $p<0.01$. 


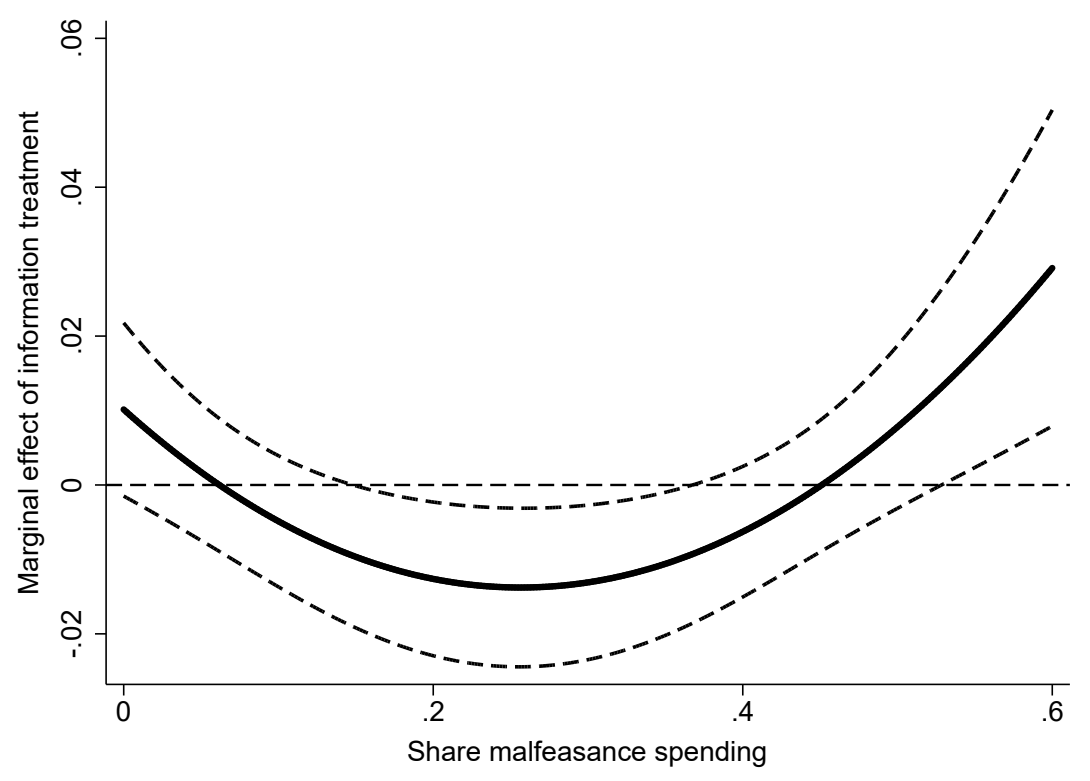

Figure 8: Marginal effect of information treatment on turnout, by share of malfeasant spending (95\% confidence intervals)

of malfeasance spending, and thus are not an artifact of our pre-specified parametric (quadratic) approach. Furthermore, although it is possible that our turnout results reflect party mobilization strategies, the results in Table 8 below suggest that political responses are concentrated in highmalfeasance municipalities, and thus cannot explain how the treatment could induce high turnout in low-malfeasance municipalities. In sum, these results indicate that revelations that substantially deviate from the average voter's prior beliefs can induce major realignments, as voters shift not just towards indifference but to support other parties.

While these results support our model that emphasizes the importance of voters' prior expectations, it is possible that voters may also disengage. However, we find no evidence to suggest that information about an incumbent's malfeasance induces a general form of disengagement with the political system (e.g. Chong et al. 2015). Column (2) of panel A shows that turnout does not significantly decrease depending on the level of malfeasant spending. Furthermore, examining a five-point scale of voters' beliefs that elections help to select honest and competent politicians in panel B, columns (4) and (5) report that high levels of malfeasance and unfavorable updating did not significantly alter voters' faith that elections can select good candidates. ${ }^{40}$

\footnotetext{
${ }^{40}$ Unreported results including a quadratic interaction with incumbent malfeasant spending provide no evidence to suggest that confidence mirrors the non-linear relationship with turnout.
} 


\section{Party responses to malfeasance revelations}

The preceding results illuminate an accountability equilibrium in which voters are willing to reward or sanction their incumbent party depending on their level of malfeasance while in office, but are characterized by sufficiently low expectations that revelations of substantial levels of malfeasance are not sufficient to induce electoral sanctioning. However, this lack of sanctioning could partially reflect political parties' responses to the provision of malfeasance information. For example, information provision reduced vote buying in India (Banerjee et al. 2011), while the opposite occurred in the Philippines (Cruz, Keefer and Labonne 2017). Bidwell, Casey and Glennerster (2016) also find evidence of politician responses to an informational intervention in Sierra Leone that are consistent with and suggestive of voter learning. Such reactions are already incorporated into our overall point estimates, which may be the primary parameter of policy interest. Nevertheless, to better understand the general equilibrium effects of providing information, we explore whether party campaign strategies could account for voting outcomes.

To examine this systematically, we asked voters whether incumbents and challengers referred to the information reported in our leaflets through the following (non-exclusive) methods: i) campaign activities, ii) partisan leaflets, iii) visits from local political actors, iv) advertisements, or v) through the media. Around $17 \%$ of voters reported at least one type of incumbent response, and $16 \%$ reported at least one type of challenger response. According to our respondents, incumbents most frequently claimed that all parties were equally bad, while opposition parties were somewhat more likely to try to emphasize the content of the leaflets. In columns (1)-(5) of Table 8 we use as a dependent variable the total number of politician responses reported by the respondent, ranging from 1 to 5, while in columns (6)-(10) we examine indicators for each type of response.

Column (1) of panels A and B identifies no significant change in incumbent responses and a slight (but significant) increase in challenger responses on average in treatment relative to control precincts. ${ }^{41}$ However, these modest increases in political activity mask the sharp increase where malfeasance revelations were most severe. The large and significant positive interactions in column (4) demonstrate that, for both incumbents and challengers, party activity increased substantially in municipalities in which high levels of malfeasance were revealed. In a treated precinct within a municipality with $50 \%$ malfeasant spending, activity almost doubled relative to a municipality with $0 \%$. However, a comparison of column (4) with columns (2), (3), and (5) indicates that political responses are driven by the level of malfeasance reported, rather than the extent to which voters updated their prior beliefs based on this information. This suggests that incumbent parties and

\footnotetext{
${ }^{41}$ The non-zero number of activities in the control group likely reflects recall failures.
} 


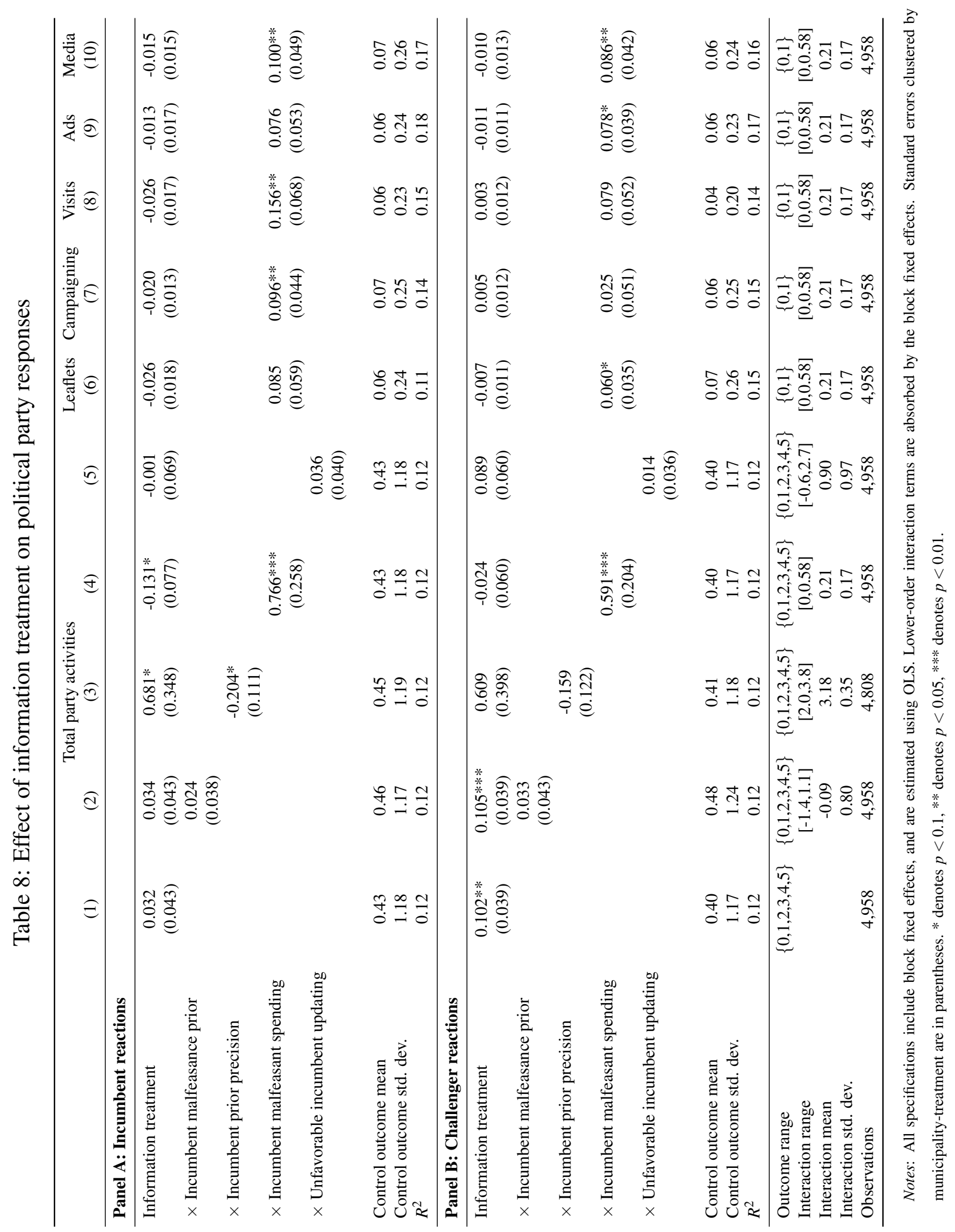


their operatives may not know the extent to which voters expect their representatives to engage in minimal malfeasant spending while in office. Columns (6)-(10) categorize the activities index and show that increased party activity in high-malfeasance treated precincts often occurs through the media. The incumbent, in particular, is also significantly more likely to engage in on-the-ground campaign and visiting tactics. ${ }^{42}$

The preceding evidence of increased party activity suggests that party responses may play an important role in understanding how information dissemination impacts incumbent party support. If such party activity influenced voting behavior, it could in part explain the positive average effect on incumbent vote share. Nevertheless, it is important to emphasize the fact that political parties do not respond in low-malfeasance municipalities and do not differentiate their responses in line with voters' prior beliefs. This demonstrates that party responses cannot account for the heterogeneity in voter responses attributed to changes in voter beliefs.

\section{Conclusion}

This article demonstrates the importance of voters' prior beliefs in understanding when incumbent malfeasance revelations affect voting behavior. We find that Mexican voters-who, like voters in many developing contexts, have low expectations that their incumbents will correctly allocate resources-on average actually reward municipal incumbent parties revealed to have engaged in non-trivial levels of malfeasance in office. Although the average positive effect may also in part reflect incumbent and challenger reactions to the information's provision, we document considerable support for our simple learning model. In particular, rewards are significantly more likely among voters who have particularly unfavorable prior beliefs about incumbent party malfeasance, who learn of lower incumbent malfeasance, and who update their beliefs about the incumbent most favorably. Furthermore, consistent with our theoretical model, turnout responds to information non-linearly: surprising information increases turnout by shifting voters between parties, and relatively unsurprising information shifts voters towards indifference. By emphasizing voters' prior beliefs, and their relationship with the content of the information, these findings can help explain the mixed evidence that information induces electoral sanctioning or impacts political participation in developing democracies.

The implications of our findings for using information interventions to improve governance are mixed. A clear reason for optimism is that voters with relatively low levels of education are able

\footnotetext{
${ }^{42}$ Unreported estimates indicate that parties did not respond differently where the treatment was delivered publicly.
} 
to understand incumbent performance information and incorporate it into their voting behavior in a simple Bayesian manner. Fixing their expectations of the parties, information thus helps voters to choose between candidates. However, the fact that some voters are so pessimistic that the misallocation of up to $40 \%$ of funds is considered good news is worrying for proponents of good governance. As the mixed evidence from previous studies suggests, such beliefs may not be uncommon in developing contexts_-and may be consistent with incumbent behavior (e.g. Caselli and Morelli 2004). Given the central importance of the interaction between voters' prior beliefs and information content, a key challenge for future research is understanding the origins of voters' prior beliefs.

Our findings suggest the need to improve voters' expectations of their elected representatives, which could induce politicians to perform better in office in the long run (Barro 1973; Ferejohn 1986), the need for better politicians to stand for office, or more effective audits and legal sanctions. Civic education or a critical media may be required to help voters understand what good performance entails (e.g. Adida et al. 2017; Botero et al. 2015; Gottlieb 2016). Higher-quality candidates should also be encouraged to stand for office; some evidence suggests that increased wages can help (Caselli and Morelli 2004; Ferraz and Finan 2011). More effective audits and legal sanctions may also help improve politicians' performance. Although it is difficult to distinguish the effects of monitoring from selection effects, the extensive use of audits also may help reduce incumbent malfeasance by causing parties to believe that they will be electorally sanctioned for malfeasance in office (Avis, Ferraz and Finan forthcoming; Bobonis, Fuertes and Schwabe 2016; Olken 2007; Zamboni and Litschig 2014).

From the perspective of providing information, it is important to understand how the means of information transmission can affect voters' responses. The largest documented effects of information on electoral accountability include the role of broadcast media (e.g. Ferraz and Finan 2008; Larreguy, Marshall and Snyder 2018), whereas leaflet-based delivery has typically yielded smaller effects. On the one hand, this is likely to partly reflect the comparatively limited reach and salience of leaflets relative to radio or television, the greater credibility of broadcast media, and the media's greater potential to support coordination by establishing common knowledge (e.g. Adida et al. 2017; Arias forthcoming; Yanagizawa-Drott 2014). ${ }^{43}$ The scale of information provision may also matter: as our discussion of political responses indicates, incumbents may be able to counteract small-scale interventions by targeting the locations exposed to damaging information (e.g. Cruz,

\footnotetext{
${ }^{43}$ Our treatment variant of including a loudspeaker to accompany leaflet delivery was designed to experimentally manipulate common knowledge. As shown in the Appendix, this had no additional effect, although the common knowledge treatment was relatively weak and the treatment could already have induced common knowledge.
} 
Keefer and Labonne 2017). In contrast, media coverage is normally more comprehensive, and may thus reach too many voters for incumbent parties to deploy targeted responses to mitigate electoral losses or induce a blanket response that affects all precincts equally. Understanding the mechanics of incumbent responses is crucial for future research.

On the other hand, the nature of updating associated with media dissemination may also be qualitatively different. In contrast with this study, estimates from prior studies suggest that voters are willing to punish lower levels of malfeasance publicized by local media. Although the sample for this study was in part selected due to its high levels of malfeasance, and likely greater prior expectations of malfeasance, future research is required to determine the extent to which differences in the sanctioning of the same revelation of malfeasance may be attributable to the media's greater capacity to frame, provide credibility, or incite tacit or explicit voter coordination. This study takes the development of prior beliefs as given, which facilitates the careful identification of information processing, but leaves open the key question of how repeated media exposure shapes the long-term formation of such beliefs.

Finally, our study underscores the importance of investigating equilibrium political responses for understanding the impact of informational interventions. As with several other recent studies (Banerjee et al. 2011; Cruz, Keefer and Labonne 2017), we find clear evidence that politicians respond to such interventions. Although the patterns of political responses in this study do not confound our capacity to estimate the effects of belief updating, to the extent that such responses can explain the average effects, the responses may be highly consequential. To better understand when informational interventions are effective, political responses demand further attention. 


\section{References}

Adida, Claire, Jessica Gottlieb, Eric Kramon and Gwyneth McClendon. 2017. "Breaking the Clientelistic Voting Equilibrium: The Joint Importance of Salience and Coordination.” Working paper.

Ansolabehere, Stephen and Shanto Iyengar. 1995. Going Negative. New York: Free Press.

Arias, Eric. forthcoming. "How Does Media Influence Social Norms? A Field Experiment on the Role of Common Knowledge.” Political Science Research and Methods .

Arias, Eric, Horacio A. Larreguy, John Marshall and Pablo Querubín. 2018. "Does the Content and Mode of Delivery of Information Matter for Electoral Accountability? Evidence from a Field Experiment in Mexico.” Working paper.

Auditoría Superior de la Federación. 2014. "Informe del Resultado de la Fiscalización Superior de la Cuenta Pública 2012.” Audit Summary Report.

Avis, Eric, Claudio Ferraz and Frederico Finan. forthcoming. "Do Government Audits Reduce Corruption? Estimating the Impacts of Exposing Corrupt Politicians." Journal of Political Economy .

Banerjee, Abhijit V., Selvan Kumar, Rohini Pande and Felix Su. 2011. "Do Informed Voters Make Better Choices? Experimental Evidence from Urban India.” Working paper.

Barro, Robert J. 1973. “The Control of Politicians: An Economic Model.” Public Choice 14(1):1942.

Besley, Timothy and Robin Burgess. 2002. "The political economy of government responsiveness: Theory and evidence from India." Quarterly Journal of Economics 117(4):1415-1451.

Bidwell, Kelly, Katherine Casey and Rachel Glennerster. 2016. "Debates: Voting and Expenditure Responses to Political Communication.” Working Paper.

Boas, Taylor, F. Daniel Hidalgo and Marcus A. Melo. 2018. "Norms versus Action: Why Voters Fail to Sanction Malfeasance in Brazil.”'Working paper.

Bobonis, Gustavo J, Luis Cámara R Fuertes and Rainer Schwabe. 2016. "Monitoring Corruptible Politicians." American Economic Review 106(8):2371-2405. 
Botero, Sandra, Rodrigo Castro Cornejo, Laura Gamboa, Nara Pavao and David W. Nickerson. 2015. "Says Who? An Experiment on Allegations of Corruption and Credibility of Sources." Political Research Quarterly 68(3):493-504.

Brennan, Geoffrey and Alan Hamlin. 1998. "Expressive Voting and Electoral Equilibrium.” Public Choice 95(1-2):149-175.

Buntaine, Mark T., Ryan Jablonski, Daniel L. Nielson and Paula M. Pickering. 2018. "SMS texts on corruption help Ugandan voters hold elected councillors accountable at the polls." Proceedings of the National Academy of Sciences 11(26):6668-6673.

Caselli, Francesco and Massimo Morelli. 2004. "Bad politicians.” Journal of Public Economics 88(3):759-782.

Casey, Katherine. 2015. "Crossing Party Lines: The Effects of Information on Redistributive Politics." American Economic Review 105(8):2410-2428.

Chang, Eric C.C., Miriam A. Golden and Seth J. Hill. 2010. "Legislative malfeasance and political accountability." World Politics 62(2):177-220.

Chong, Alberto, Ana De La O, Dean Karlan and Leonard Wantchekon. 2015. "Does Corruption Information Inspire the Fight or Quash the Hope? A Field Experiment in Mexico on Voter Turnout, Choice and Party Identification.” Journal of Politics 77(1):55-71.

Cinta, Alberto. 1999. Uncertainty and Electoral Behavior in Mexico in the 1997 Congressional Elections. In Towards Mexico's Democratization, ed. Jorge Domínguez and Alejandro Poiré. Routledge pp. 174-202.

Cruz, Cesi, Philip Keefer and Julien Labonne. 2017. "Buying Informed Voters: New Effects of Information on Voters and Candidates." Working paper.

de Figueiredo, Miguel F.P., F. Daniel Hidalgo and Yuri Kasahara. 2013. "When Do Voters Punish Corrupt Politicians? Experimental Evidence from Brazil.” Working paper.

Dunning, Thad, Guy Grossman, Macartan Humphreys, Susan Hyde and Craig McIntosh. forthcoming. Metaketa I: The Limits of Electoral Accountability. Cambridge University Press.

Fearon, James D. 1999. Electoral Accountability and the Control of Politicians: Selecting Good Types versus Sanctioning Poor Performance. In Democracy, Accountability, and Representation, ed. Adam Przeworski, Susan Stokes and Bernard Manin. Cambridge University Press. 
Ferejohn, John. 1986. "Incumbent performance and electoral control." Public Choice 50(1):5-25.

Ferraz, Claudio and Frederico Finan. 2008. "Exposing corrupt politicians: The effects of Brazil's publicly released audits on electoral outcomes." Quarterly Journal of Economics 123(2):703745 .

Ferraz, Claudio and Frederico Finan. 2011. "Motivating Politicians: The Impacts of Monetary Incentives on Quality and Performance.” Working paper.

Gottlieb, Jessica. 2016. "Greater Expectations: A Field Experiment to Improve Accountability in Mali.” American Journal of Political Science 60(1):143-157.

Hsieh, Chang-Tai and Enrico Moretti. 2006. "Did Iraq Cheat the United Nations? Underpricing, Bribes, and the Oil for Food Program." Quarterly Journal of Economics 121(4):1211-1248.

Humphreys, Macartan and Jeremy Weinstein. 2012. "Policing Politicians: Citizen Empowerment and Political Accountability in Uganda Preliminary Analysis." Working paper.

Iyengar, Shanto. 1991. Is anyone responsible? How television frames political issues. University of Chicago Press.

Kendall, Chad, Tommaso Nannicini and Francesco Trebbi. 2015. "How Do Voters Respond to Information? Evidence from a Randomized Campaign.” American Economic Review 105(1):32253.

Khemani, Stuti, Ernesto Dal Bó, Claudio Ferraz, Frederico S. Finan, Johnson Stephenson, Louise Corinne, Adesinaola M. Odugbemi, Dikshya Thapa and Scott D. Abrahams. 2016. "Making politics work for development: Harnessing transparency and citizen engagement." World Bank Policy Research Report 106337.

Laakso, Markku and Rein Taagepera. 1979. "“Effective” number of parties: a measure with application to West Europe." Comparative Political Studies 12(1):3-27.

Langston, Joy. 2003. "Rising from the ashes? Reorganizing and unifying the PRI's state party organizations after electoral defeat." Comparative Political Studies 36(3):293-318.

Larreguy, Horacio A., John Marshall and Jr. Snyder, James M. 2018. "Publicizing Malfeasance: How Local Media Faciliates Electoral Sanctioning of Mayors in Mexico.” Working paper. 
Larreguy, Horacio A., John Marshall and Jr. Snyder, James M. forthcoming. "Leveling the playing field: How equalizing access to campaign advertising helps locally non-dominant parties in consolidating democracies." Journal of the European Economic Association .

Larreguy, Horacio A., John Marshall and Pablo Querubín. 2016. "Parties, Brokers and Voter Mobilization: How Turnout Buying Depends Upon the Party's Capacity to Monitor Brokers." American Political Science Review 110(1):160-179.

Leon, Gianmarco. 2017. "Turnout, Political Preferences and Information: Experimental Evidence from Peru." Journal of Development Economics 127:56-71.

Magaloni, Beatriz. 2006. Voting for Autocracy: Hegemonic Party Survival and its Demise in Mexico. New York: Cambridge University Press.

Marshall, John. 2018. "Political information cycles: When do voters sanction incumbent parties for high homicide rates?" Working paper.

Mauro, Paolo. 1995. “Corruption and Growth.” Quarterly Journal of Economics 110(3):681-712.

Morgenstern, Scott and Elizabeth Zechmeister. 2001. "Better the devil you know than the saint you don't? Risk propensity and vote choice in Mexico.” Journal of Politics 63(1):93-119.

Morris, Stephen and Hyun Song Shin. 2002. "Social value of public information." American Economic Review 92(5):1521-1534.

Olken, Benjamin A. 2007. "Monitoring Corruption: Evidence from a Field Experiment in Indonesia." Journal of Political Economy 115(2):200-249.

Rogoff, Kenneth. 1990. "Equilibrium Political Budget Cycles.” American Economic Review 80(1):21-36.

Snyder, James M., Jr. and David Strömberg. 2010. "Press Coverage and Political Accountability." Journal of Political Economy 118(2):355-408.

Wellenstein, Anna, Angélica Núñez and Luis Andrés. 2006. Social Infrastructure: Fondo de Aportaciones para la Infraestructura Social (FAIS). In Decentralized service delivery for the poor, Volume II: Background papers, ed. The World Bank. Mexico City: The World Bank pp. 167-222. 
Yanagizawa-Drott, David. 2014. "Propaganda and Conflict: Evidence from the Rwandan Genocide.” Quarterly Journal of Economics 129(4):1947-1994.

Zamboni, Yves and Stephan Litschig. 2014. "Audit Risk and Rent Extraction: Evidence from a Randomized Evaluation in Brazil.” Working paper. 